\title{
CARACTERIZACIÓN GEOQUÍMICA Y PETROGRÁFICA DE LAS UNIDADES GEOLÓGICAS DEL MACIZO DEL VOLCÁN POÁS, COSTA RICA
}

\section{GEOCHEMICAL AND PETROGRAPHICAL CHARACTERIZATION OF THE GEOLOGICAL UNITS OF POÁS VOLCANO MASSIF, COSTA RICA}

\author{
Pablo Ruiz ${ }^{1 *}$, Esteban Gazel², Guillermo E. Alvarado ${ }^{3,4}$, \\ Michael J. Carr ${ }^{1} \&$ Gerardo J. Soto $3,4,5$ \\ ${ }^{1}$ Department of Earth and Planetary Sciences, Rutgers University, \\ 610 Taylor Rd. Piscataway, NJ 08854, EE. UU. \\ ${ }^{2}$ Lamont-Doherty Earth Observatory, Columbia University, EE. UU. \\ ${ }^{3}$ Instituto Costarricense de Electricidad (ICE) \\ ${ }^{4}$ Escuela Centroamericana de Geología, Universidad de Costa Rica \\ ${ }^{5}$ Terra Cognita Consultores \\ *Autor para contacto: pruiz@rci.rutgers.edu
}

(Recibido: 20/05/2009; aceptado: 08/11/2010)

\begin{abstract}
The present study defines the stratigraphy of Poás volcano by using geologic, petrographic, geochronologic and geochemical analyses made on the Poás units. The northern flank of the volcano is comprised of the following units: Río Sarapiquí, La Paz Andesites, Tiribí Formation (from Barva volcano, but interdigitated with Poás stratigraphy), Río Cuarto Lavas, Von Frantzius, Cerro Congo, Bosque Alegre and Laguna Kopper. The units on the southern flank are Colima Formation, La Paz Andesites, Tiribí, Achiote, Poasito, Sabana Redonda and Poás Lapilli Tuff. The central part of the volcano is made by the Poás Summit Unit, which includes the Main and Botos craters. The composition of the rocks spans the range from basalts to dacites. These units were geochemically correlated with two magmatic components: 1 . The Sabana Redonda Geochemical Component $\left(\mathrm{TiO}_{2}>1 \%\right)$ enriched in HSFE and other trace elements, present in La Paz Andesites, Lavas Río Cuarto, Poasito, Sabana Redonda, Poás Lapilli Tuff and some from Botos crater lavas. 2. The Von Frantzius Geochemical Component $\left(\mathrm{TiO}_{2}<0.8 \%\right)$ is present in lavas of the Main crater, Von Frantzius, Achiote, Bosque Alegre, Cerro Congo and some Botos crater lavas. During the last $600 \mathrm{ka}$ the content of $\mathrm{K}_{2} \mathrm{O}$ and other oxides $\left(\mathrm{TiO}_{2}\right.$ and $\left.\mathrm{P}_{2} \mathrm{O}_{5}\right)$ and traces $(\mathrm{Zr}, \mathrm{Ba})$ have varied significantly through time, suggesting the presence of these two geochemical end-members since the beginning of the magmatic activity of Poás. Within similar ranges of time, units with high and low values of these elements have coexisted; the latter is true for Botos lavas
\end{abstract}


and the Main crater. For units that possibly shared a common vent, such as La Paz Andesites, Achiote and Main crater, the percentages of $\mathrm{K}_{2} \mathrm{O}$ and $\mathrm{TiO}_{2}$ have decreased through time. Nevertheless, more geochronological data are needed to improve the interpretations given above.

Keywords: Poás, geology, geochemistry, geochronology, volcanology, volcano-stratigraphy.

RESUMEN: En este estudio definimos la estratigrafía del volcán Poás con base en la geología, petrografía, geocronología y geoquímica de sus unidades. El sector norte está constituido por las unidades Río Sarapiquí, Andesitas La Paz, Formación Tiribí (del volcán Barva, pero interdigitada), Lavas Río Cuarto, Von Frantzius, Cerro Congo, Bosque Alegre y Laguna Kopper. El sector sur está constituido por la Formación Colima, Unidad Andesitas La Paz, Formación Tiribí y las unidades Achiote, Poasito, Sabana Redonda y la Toba de Lapilli Poás. Mientras que el sector central está conformado por la unidad Cima del Poás que incluye los productos de los cráteres Principal y Botos. Las rocas de estas unidades varían desde basaltos hasta dacitas y se pueden correlacionar geoquímicamente con los componentes magmáticos del Poás: 1) Componente Geoquímico Sabana Redonda, con valores de $\mathrm{TiO}_{2}>1 \%$, y enriquecido en HFSE y trazas, presente en las unidades Andesitas La Paz, Lavas Río Cuarto, Poasito, Sabana Redonda, la Toba de Lapilli Poás y algunas lavas del cráter Botos. 2) Componente Geoquímico Von Frantzius con valores de $\mathrm{TiO}_{2}<0,8 \%$, presente en las lavas de la zona del cráter Principal, Von Frantzius, las Unidades Achiote, Bosque Alegre, Cerro Congo y algunas lavas del cráter Botos. Durante los últimos $600 \mathrm{ka}$ el contenido de $\mathrm{K}_{2} \mathrm{O}$ y otros elementos mayores como $\mathrm{TiO}_{2}$ y $\mathrm{P}_{2} \mathrm{O}_{5}$, y las trazas $\mathrm{Zr}$, Ba han variado significativamente a través del tiempo en estas unidades, evidenciando la presencia de estos dos componentes desde los inicios de la actividad magmática del Poás. En rangos de tiempo similares estos dos componentes geoquímicos han coexistido, como es el caso de las lavas de los cráteres Botos y Principal. En unidades con un centro de emisión similar como Andesitas la Paz, Achiote y Cráter Principal, el contenido de $\mathrm{K}_{2} \mathrm{O}$ y TiO $\mathrm{Ti}_{2}$ ha disminuido a través del tiempo. Sin embargo, más datos geocronológicos son necesarios para mejorar estas interpretaciones.

Palabras clave: Poás, geología, geoquímica, geocronología, vulcanología, volcano-estratigrafía.

\section{INTRODUCCIÓN}

El volcán Poás se encuentra localizado en la sección noroeste de la Cordillera Volcánica Central (CVC) de Costa Rica. Su actual foco eruptivo se ubica dentro de una fractura volcano-tectónica alineada norte-sur, En esta fractura también se encuentran ubicados los conos piroclásticos de Sabana Redonda, el cono Botos, el cono Von Frantzius, el volcán Congo y los maares de Hule y Río Cuarto (Prosser, 1983; Soto \& Alvarado, 1989, Fig. 1). Los flancos norte y sur del edificio volcánico están delimitados por los escarpes de las fallas inversas de San Miguel y Alajuela, respectivamente. Además existen otras estructuras tectónicas (especialmente fallas de desplazamiento de rumbo) localizadas en los flancos este y oeste del volcán con actividad sísmica histórica y destructiva. Entre los terremotos más importantes están el de $1851\left(\mathrm{M}_{\mathrm{s}} 6,0\right)$, el de $1888\left(\mathrm{M}_{\mathrm{s}} 6,0\right)$ y $2009\left(M_{w} 6,2\right)$ todos con epicentros localizados en el área de Fraijanes-Vara Blanca-Poás (Peraldo \& Montero 1999; Montero et al., 2010).
El cráter principal del volcán Poás, localizado $20 \mathrm{~km}$ al norte de la ciudad de Alajuela y tan solo a $30 \mathrm{~km}$ al NW de la capital San José (Fig. 1), ha presentado actividad volcánica en los últimos 200 años, caracterizada por un proceso de frecuentes explosiones freáticas (Alvarado, 2009) $\mathrm{y}$ actividad fumarólica continua.

La mayoría de las laderas del macizo son utilizadas para actividades agrícolas o ganaderas. Sin embargo, debido a que el Parque Nacional Volcán Poás es uno de los más visitados en el país, en las últimas dos décadas, el turismo se ha convertido en la mayor actividad económica desarrollada en el volcán y sus alrededores. Desde la década de los ochenta del siglo pasado, el Instituto Costarricense de Electricidad (ICE) y empresas privadas han construido una serie de proyectos hidroeléctricos en el sector norte del Poás, aprovechando la alta precipitación de la zona y las pendientes de las laderas del volcán para generar electricidad. Muchos de los estudios geológicos desarrollados en la zona se llevaron a cabo por la necesidad de caracterizar geológicamente las áreas de construcción de estos proyectos. 
El objetivo principal del presente trabajo es mostrar las relaciones estratigráficas, geoquímicas y petrográficas de las principales unidades geológicas que componen todo el macizo del volcán Poás. Para esto se han compilado todos los análisis químicos y geocronológicos $\left({ }^{14} \mathrm{C} \mathrm{y}{ }^{40} \mathrm{Ar} /{ }^{39} \mathrm{Ar}\right)$ que se han realizado hasta la fecha.

El área de estudio se dividió en dos sectores con centro en el cráter activo del Poás: norte y sur. El sector norte lo comprenden las unidades geológicas ubicadas desde el poblado de Río Cuarto hasta el cráter Principal. Hacia el este y el oeste se extiende hasta los ríos Sarapiquí y Toro, respectivamente (Fig. 1). El sector sur lo comprenden las unidades geológicas ubicadas desde el cráter Principal hasta el escarpe de la falla de Alajuela. Los limites hacia el este y el oeste son los ríos Tambor y Sarchí, respectivamente (Fig. 1).

\section{Trabajos previos en el volcán Poás}

La importancia que representa el volcán Poás por su actividad histórica, la cercanía de las principales ciudades y su relativa facilidad de accesar el cráter, ha permitido que se realicen numerosos trabajos científicos en temas como cartografía geológica y geoquímica.

Entre los primeros estudios está el de Kussmaul \& Sprechmann (1982), quienes propusieron que las lavas eruptadas de la actual CVC pertenecen a la Formación Andesitas Poás, con el Poás como estratotipo. Posteriormente Kussmaul et al. (1982) hicieron una recopilación de los análisis químicos realizados en Costa Rica hasta esa fecha, y realizaron una clasificación e interpretación geoquímica de las rocas ígneas de Costa Rica. De las 200 muestras utilizadas en dicho trabajo, tan solo 10 de ellas corresponden con unidades volcánicas relacionadas con el volcán Poás.

Tournon (1984) diferenció geoquímicamente los rasgos del vulcanismo cuaternario calcoalcalino de Costa Rica en tres secciones: Valle Central Oriental, Valle Central Occidental (donde está incluido el volcán Poás) y la Cordillera Volcánica de Guanacaste. Paniagua (1985) presentó análisis químicos de elementos mayores y trazas de las ignimbritas del Valle Central y de los miembros más básicos de la serie del macizo del volcán Poás.

Alvarado \& Climent (1985) y Alvarado (1985) presentaron un mapa geológico de la parte oeste de la hoja Poás y el este de la adyacente hoja Quesada. Posteriormente, Prosser \& Carr (1987) realizaron un cartografiado y muestreo geoquímico en el cráter activo del Poás, y en la zona de Sabana Redonda, donde describen al menos tres series magmáticas que varían desde de basaltos a dacitas. Dos de estas series se caracterizan por tener altos contenidos de $\mathrm{TiO}_{2}(>0,90 \%)$ y la restante por altos contenidos de $\mathrm{Al}_{2} \mathrm{O}_{3}(>18,25 \%)$. Posteriormente, Cigolini et al. (1991) realizaron análisis petrológicos de las secuencias cuspidales del Poás y concluyeron que existen diferencias geoquímicas significativas entre las lavas procedentes de los cráteres Principal y Botos.

Kussmaul (1988) hizo una comparación petrológica entre el piso volcánico del Valle Central y la CVC con base en análisis geoquímicos recopilados de varios autores, definiendo que las lavas de los estratovolcanes, incluyendo el Poás, tienen una asociación basáltico-andesítica, típicamente calcoalcalina. Además, especifica que el Poás presenta valores normales de $\mathrm{K}_{2} \mathrm{O}$ y no tan altos como el Barva e Irazú.

Borgia et al. (1990) realizaron un mapa geológico del sector sur del Poás y propusieron un modelo estructural para la falla de Alajuela y el escarpe de San Miguel, relacionado con periodos de inflamiento del volcán por intrusiones de magma. Malavassi (1991) realizó análisis geoquímicos de muestras de las localidades de Sabana Redonda y Laguna Hule.

Rojas (1993) realizó un mapeo a escala 1:10 000 de la zona del maar Laguna Hule. Complementando los estudios en la zona norte del Poás, Soto (1999), realizó un mapeo y caracterización geológica, geoquímica y petrográfica de las unidades de la hoja Poás.

Alvarado \& Salani (2004) hicieron un detalle de la estratigrafía de los volcanes Congo y Hule para determinar su peligro volcánico.

Los trabajos más recientes de cartografiado y geoquímica en el sector sur del volcán Poás 


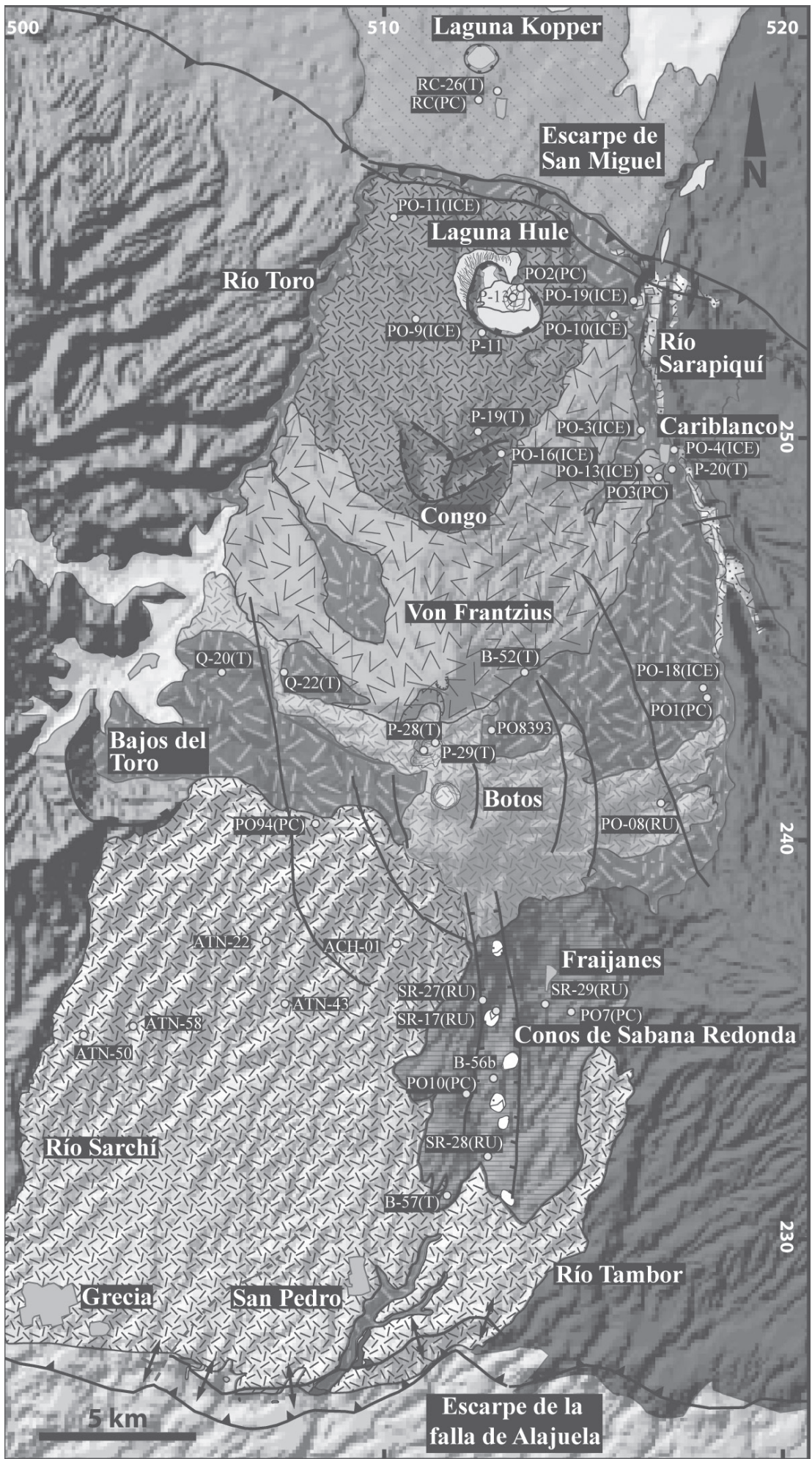

Revista Geológica de América Central, 43: 37-66, 2010 / ISSN: 0256-7024 


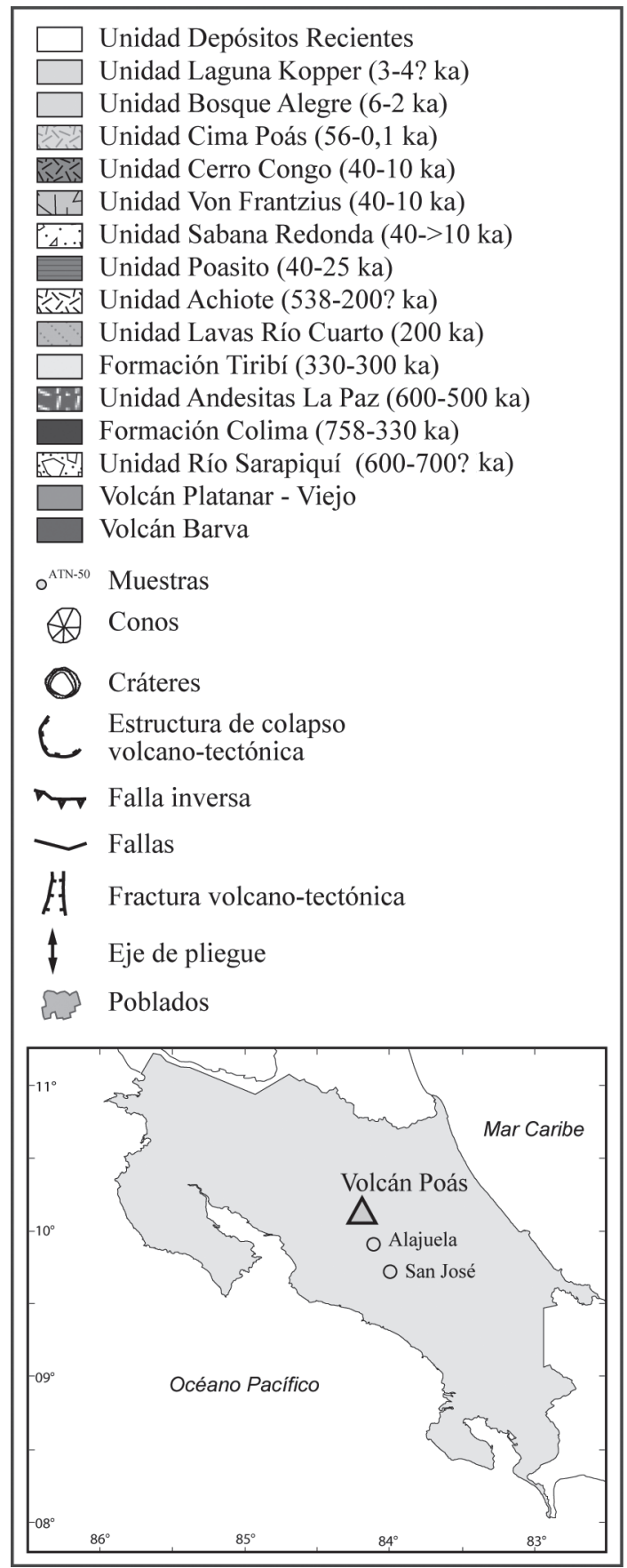

Fig. 1: Mapa geológico del Volcán Poás. Se muestran las unidades litológicas así como la ubicación de las muestras más representativas utilizadas para la base de datos geoquímica. Basado en Prosser (1983); Alvarado \& Climent (1985); Borgia et al. (1990); Rojas (1993); Alvarado \& Carr (1993); Soto (1999); Campos et al., (2004); Gazel \& Ruiz (2005) y Montes (2007). son los de Campos et al. (2004), que realizaron el mapa geológico, estudios de suelo y ubicación de pozos y nacientes de agua del cantón Poás. Luego, Gazel \& Ruiz (2005), detallaron el cartografiado geológico y una caracterización geoquímica de la zona de Sabana Redonda y las implicaciones para las series magmáticas del Poás. Además, definieron dos posibles componentes magmáticos para el Poás, uno con valores de $\mathrm{TiO}_{2}>1 \%$, enriquecido en elementos de alto equipotencial (HFSE, $\mathrm{TiO}_{2}, \mathrm{Zr}, \mathrm{Nb}$ ) y otros elementos incompatibles como $\mathrm{P}_{2} \mathrm{O}_{5}$ y K $\mathrm{K}_{2} \mathrm{O}$. Este componente lo presentan, además de la Unidad Sabana Redonda, la Unidad Poasito, Unidad Andesitas La Paz, la Toba de Lapilli Poás y algunas lavas del cráter Botos. El otro componente, con valores de $\mathrm{TiO}_{2}<0,8 \%$ está presente en las lavas de la zona del cráter Principal, el cono Von Frantzius, la Laguna Hule y algunas lavas del cráter Botos. Además, se define que las lavas con composiciones intermedias ( $\mathrm{TiO}_{2}$ 0,8-1\%) son híbridos entre estos dos componentes. Posteriormente, Montes (2007) presentó un mapa geológico para el cantón de Grecia.

El trabajo de Carr et al. (2007) incluye volúmenes para los volcanes de la CVC y nuevas dataciones para lavas pertenecientes al volcán Poás, específicamente las que afloran en el sector de Río Cuarto. El volumen calculado para el volcán Poás fue de $97 \mathrm{~km}^{3}$. Finalmente, Soto et al. (2008) correlacionaron química y litológicamente un depósito ignimbrítico mapeado en el río Sarapiquí, cerca de la confluencia con el río María Aguilar, con la Formación Tiribí.

\section{Metodología}

El mapa geológico simplificado del volcán Poás que se presenta en este trabajo (Fig. 1), se realizó con base en la compilación de diferentes mapas geológicos elaborados en la zona por diferentes autores (Prosser, 1983; Alvarado, 1985; Borgia et al., 1990; Rojas, 1993; Alvarado \& Carr, 1993; Soto, 1999; Campos et al., 2004; Gazel \& Ruiz, 2005 y Montes, 2007). Además, se completaron zonas específicas con giras de campo y análisis e interpretación de las fotografías aéreas y oblicuas, donde se detallaron y modificaron algunos 
contactos propuestos anteriormente y además, se definieron nuevas unidades geológicas. Se utilizó la base cartográfica de las hojas Poás, Barva, Río Cuarto, Quesada y Naranjo a escala 1:50 000 del IGN para la construcción del modelo de elevación digital (MED) que se utilizó como base para el mapa presentado en este estudio (Fig. 1). También se realizó una recopilación de las dataciones realizadas con diferentes metodologías por diferentes autores, incluyendo tres nuevas dataciones ${ }^{40} \mathrm{Ar} /{ }^{39} \mathrm{Ar}$, de unidades del sector Sur y central del Poás (dos muestras de la Unidad Achiote y una muestra de Botos distal; Cuadro 1); analizadas en el laboratorio de gases nobles de la Universidad de Rutgers y siguiendo la metodología expuesta en Carr et al. (2007).

También presentamos una compilación de descripciones de secciones delgadas de diferentes unidades lávicas del Poás, realizadas por diferentes autores (Campos et al., 2004; Montes, 2007), así como descripciones propias de los autores de este trabajo (Cuadro 2). Adicionalmente, se utilizó información de las descripciones de núcleos de perforación de los proyectos Hule y Cariblanco realizados por el ICE para afinar correlaciones y determinar espesores de la unidades.

La base de datos de geoquímica utilizada en este trabajo incluye 136 análisis, tomados de recopilaciones anteriores de Kussmaul et al., (1982), Kussmaul, (1988) y de diferentes autores: McBirney \& Williams (1965); Krushensky \& Escalante (1967); Thorpe et al. (1981); Prosser (1983); Tournon (1984); Alvarado (1985); Paniagua (1985); Prosser \& Carr (1987); Cigolini et al. (1991); Malavassi (1991); Soto (1999); Patino et al. (2000); Carr (2002); Gazel \& Ruiz (2005) y Carr et al. (2007). Fue completada con 11 nuevos análisis químicos de muestras recolectadas en la zona de Grecia (Unidad Achiote, 5 análisis), el sector del poblado Sabana Redonda (Unidad Poasito, 3 análisis; y Unidad Sabana Redonda, 2 análisis) y en el flanco este del cráter Botos (Unidad Cima Poás, 1 muestra).

Las 11 muestras nuevas fueron pulverizadas en el laboratorio de geoquímica de la Universidad de Rutgers, posteriormente enviadas a la Universidad Estatal de Michigan, donde se prepararon discos homogéneos de vidrio con $\sim 10$ gramos de la muestra pulverizada junto con tetraborato de litio $\left(\mathrm{Li}_{2} \mathrm{~B}_{4} \mathrm{O}_{7}\right)$. Dos tipos de análisis geoquímicos para roca total fueron llevados a cabo. El primer tipo consistió en fluorescencia de rayos $\mathrm{X}(\mathrm{XRF})$, con equipo tipo Bruker S4 Pionner, para elementos mayores y elementos traza seleccionados (por ejemplo, Ni, Rb, Sr, Zr, Zn y $\mathrm{Cu}$ ). El segundo tipo fue realizado mediante la técnica de separación láser inducida por espectrometría de plasma (LA-ICP-MS) para medir concentraciones de elementos traza utilizando una plataforma de micro masa (ICP-MS) con un láser de $266 \mathrm{~nm}$ Cetac LSX 200+ Nd YAG. Mayores detalles sobre la metodología, estandarización y precisión se pueden encontrar en Hannah et al. (2002). Los análisis químicos se graficaron y modelaron usando el programa IGPET 2009.

Con la ubicación geográfica de cada una de las muestras recopilada, se sobrepuso un mapa de ubicación de muestras sobre el mapa geológico realizado para este trabajo (Fig. 1) y de esta forma se asignó la respectiva unidad geológica a la que pertenece cada una de las muestras. En varios casos algunas muestras se encontraban muy cerca del contacto geológico entre dos unidades, por lo que se realizaron visitas al sitio donde fueron originalmente tomadas y se determinó a cuál unidad correspondían. A pesar de que los análisis compilados para esta base de datos provienen de diferentes autores, laboratorios, técnicas y algunos de ellos se realizaron hace más de 20 años, hay bastante homogeneidad en los datos. En ninguno de los artículos consultados para compilar la base de datos geoquímica, se encontró información sobre las incertidumbres de los análisis. Sin embargo, actualmente se maneja que para los análisis de elementos mayores obtenidos con XRF, la incertidumbre es proporcional a la concentración del elemento analizado y que no debería superar un $2 \%$ en elementos mayores y $6 \%$ para las tierras raras.

Para la caracterización geoquímica de la Unidad Achiote se utilizaron 10 análisis químicos, de los cuales cinco son nuevos. Los otros cinco análisis son de Prosser (1983) y provienen de muestras tomadas en un corte en el Cerro Pelón, al suroeste del cráter principal e interpretadas anteriormente como pertenecientes a la parte basal del cono Botos. Con base en comparaciones 
Cuadro 1

Dataciones realizadas en unidades litológicas pertenecientes al volcán Poás

\begin{tabular}{|c|c|c|c|}
\hline Unidad & Método & Edad (ka) & Referencia y comentarios \\
\hline Fm. Colima & ${ }^{40} \mathrm{Ar} /{ }^{39} \mathrm{Ar}$ & $758-330$ & $\begin{array}{l}\text { Marshall \& Idleman (1999), } \\
\text { Marshall et al. (2003) } \\
\text { Gans et al. (2003) }\end{array}$ \\
\hline U.And. La Paz & ${ }^{40} \mathrm{Ar} /{ }^{39} \mathrm{Ar}$ & $\begin{array}{l}514 \pm 24 \\
527 \pm 6 \\
610 \pm 36\end{array}$ & Gans, com. oral (2004) \\
\hline U. Achiote & ${ }^{40} \mathrm{Ar} /{ }^{39} \mathrm{Ar}$ & $\begin{array}{l}283 \pm 15 \\
538 \pm 15\end{array}$ & Este trabajo \\
\hline Fm. Tiribí & ${ }^{40} \mathrm{Ar} /{ }^{39} \mathrm{Ar}$ & $322 \pm 2$ & Pérez et al. (2006) \\
\hline U. Lavas Río Cuarto & ${ }^{40} \mathrm{Ar} /{ }^{39} \mathrm{Ar}$ & $201 \pm 30$ & Carr et al. (2007) \\
\hline U. Congo & ${ }^{14} \mathrm{C}$ & $35,6 \pm 0,6$ & $\begin{array}{l}\text { Malavassi et al. 1990, calibrada en este } \\
\text { trabajo usando Van der Plicht et al. } \\
\text { (2004), posible edad de primeros eventos }\end{array}$ \\
\hline \multirow[t]{2}{*}{ U. Von Frantzius } & ${ }^{40} \mathrm{Ar} /{ }^{39} \mathrm{Ar}$ & $41 \pm 2$ & Gans, com. oral (2004) \\
\hline & ${ }^{14} \mathrm{C}$ & $>46,60$ & $\begin{array}{l}\text { Este trabajo: lahares que subyacen } \\
\text { a Von Frantzius en su extremo nor- } \\
\text { este, son más viejos que esa edad. }\end{array}$ \\
\hline U. Sabana Redonda & ${ }^{14} \mathrm{C}$ & $40,04+1,37-2,40$ & $\begin{array}{l}\text { Este trabajo, calibrada usan- } \\
\text { do Van der Plicht et al (2004) }\end{array}$ \\
\hline \multirow[t]{4}{*}{ U. Cima Poás (Botos) } & ${ }^{14} \mathrm{C}$ & $8,330 \pm, 070-0,160$ & $\begin{array}{l}\text { Prosser \& Carr (1987), calibrada } \\
\text { y reinterpretada por Soto (1999) }\end{array}$ \\
\hline & & $10,890 \pm 0,300$ & $\begin{array}{l}\text { Malavassi et al. 1990, calibrada en este } \\
\text { trabajo usando CALIB REV 5.0.2* }\end{array}$ \\
\hline & & $11,360 \pm 0,250$ & $\begin{array}{l}\text { Malavassi et al. 1990, calibrada en este } \\
\text { trabajo usando CALIB REV 5.0.2* }\end{array}$ \\
\hline & ${ }^{40} \mathrm{Ar} /{ }^{39} \mathrm{Ar}$ & $56 \pm 4$ & Este trabajo \\
\hline \multirow[t]{3}{*}{ U. Bosque Alegre } & ${ }^{14} \mathrm{C}$ & $\sim 6,2$ & $\begin{array}{llll}\text { Melson et al. (1988) } & \text { y } & \text { Soto } \\
(1999), & \text { reinterpretadas por } & \text { Al- }\end{array}$ \\
\hline & & & varado \& Salani $\quad(2004, \quad 2009)$ \\
\hline & & $2,79 \pm 0,070-0,020$ & Malavassi et al. (1990) \\
\hline U. Lapilli Poás & ${ }^{14} \mathrm{C}$ & $40-3,3 \pm 1$ & Prosser \& Carr (1987) \\
\hline
\end{tabular}

*: RADIOCARBON CALIBRATION PROGRAM, CALIB REV5.0.2, (C1986-2005 por M Stuiver \& PJ Reimer, disponible en: http://calib.qub.ac.uk/calib/calib.html

geoquímicas con los análisis nuevos de la Unidad Achiote, y estudios con fotografías aéreas y oblicuas, se determinó que estas muestras corresponden a la Unidad Achiote y no al cono Botos.

Para caracterizar geoquímicamente la unidad Bosque Alegre se utilizaron 12 análisis químicos, presentados por McBirney \& Williams (1965), Tournon (1984), Malavassi (1991) y Soto (1999). La muestra PO-09 de Soto (1999), fue reinterpretada para este trabajo como de la Unidad Bosque Alegre, y no de la Unidad Cerro Congo.

Thorpe et al. (1981) presentaron tres análisis químicos de lavas del Poás, incluidos luego en Kussmaul (1988). Sin embargo, por falta de una ubicación geográfica exacta, no fue posible asignarles alguna de las unidades geológicas mencionadas en este trabajo, razón por la cual no se incluyen en los diagramas realizados con la base de datos. 
Cuadro 2

Composición petrográfica de las principales unidades geológicas que componen el macizo del volcán Poás

\begin{tabular}{|c|c|c|c|c|}
\hline Código & Coordenadas & Descripción microscópica & Clasificación & Unidad/Formación \\
\hline N5-27-7-04 & $\begin{array}{l}509479 \mathrm{E} \\
227279 \mathrm{~N}\end{array}$ & $\begin{array}{l}\text { Textura fluidal. Matriz }(88 \%) \text { con fiames y tex- } \\
\text { turas de flujo. Fenocristales: }(4 \%) \text {, Plagioclasa } \\
(3 \%) \text { idiomorficas a hipidiomórficas. Clinopirox- } \\
\text { eno }(1 \%) \text { hipidiomórficas. Vesículas: ( } 8 \% \text { ) de } \\
\text { forma alargada y dispuestas en la dirección de flujo }\end{array}$ & Ignimbrita & Form. Tiribí \\
\hline PO-01 & $\begin{array}{l}518350 \mathrm{E} \\
243350 \mathrm{~N}\end{array}$ & $\begin{array}{l}\text { Textura fanerítica-porfirítica. Matriz: ( } 72 \%) \text { Textura } \\
\text { hialopilítica con microlitos de plagioclasa. Fenocris- } \\
\text { tales: }(28 \%) \text {. Plagioclasa: }(15 \%) \text { megafenocristales } \\
\text { idiomorficos-hipidiomórficos }(2-3 \mathrm{~cm}) \text {. Olivino: } \\
4 \% \text { hipidiomórficos-xenomórfico con iddingsita. } \\
\text { Clinopiroxeno( } 8 \% \text { )hipidiomórficos, magnetita( } 1 \%)\end{array}$ & Andesita basáltica & $\begin{array}{l}\text { Unid. Andesitas } \\
\text { La Paz }\end{array}$ \\
\hline R4-1/7/01-2 & $\begin{array}{l}509881 \mathrm{E} \\
260814 \mathrm{~N}\end{array}$ & $\begin{array}{l}\text { Textura afanítica porfirítica. Matriz ( } 94 \% \text { ), Textura } \\
\text { hialina fluidal, pliegues y dirección preferencial } \\
\text { en el eje largo de los fenocristales y de la matriz. } \\
\text { Fenocristales }(6 \%) \text {. Plagioclasa ( } 3-4 \% \text { ) idiomórfi- } \\
\text { cas, augita }(2 \%) \text { hipidiomórficas y olivinos }(1 \%)\end{array}$ & $\begin{array}{l}\text { Andesita con } \\
\text { olivino }\end{array}$ & $\begin{array}{c}\text { Unid.Lavas Río } \\
\text { Cuarto }\end{array}$ \\
\hline ATN-58 & $\begin{array}{l}503517 \mathrm{E} \\
234834 \mathrm{~N}\end{array}$ & $\begin{array}{l}\text { Textura hipocristalina porfirítica seriada. } \\
\text { Matriz:(80\%) Textura intersertal, microlitos de } \\
\text { plagioclasas en una red irregular, augitas. Fenoc- } \\
\text { ristales: }(20 \%) \text {, Plagioclasas: }(17 \%) \text { hipidiomórfi- } \\
\text { cas a xenomórficas corroídas, } 3 \times 1.6 \mathrm{~mm} \text {. Ol- } \\
\text { ivinos: }(3 \%) \text {, en fenocristales hipdiomórficos } \\
\text { a xenomórficos con iddingzita, } 0.4 \times 0.3 \mathrm{~mm}\end{array}$ & $\begin{array}{l}\text { Andesita con } \\
\text { olivino }\end{array}$ & Unid. Achiote \\
\hline PO-8 & $\begin{array}{l}513400 \mathrm{E} \\
233900 \mathrm{~N}\end{array}$ & $\begin{array}{l}\text { Textura hipocristalina-porfirítica. Matriz: } 95 \% \text { con } \\
\text { textura hialina de aspecto fluidal. Fenocristales: } 5 \\
\% \text { en cumulitos. Plagioclasas: }(2 \%) \text { idiomórficas. } \\
\text { Clinopiroxeno( } 2 \%) \text {, hipidiomórfico, magnetita( } 1 \%)\end{array}$ & Andesita basáltica & Unid. Poasito \\
\hline SR-26704-2 & $\begin{array}{l}513360 \mathrm{E} \\
233770 \mathrm{~N}\end{array}$ & $\begin{array}{l}\text { Textura escoriácea, microcristales de plagioclasa } \\
\text { en una matriz vitrea de color negro. Fenocristales } \\
\text { de plagioclasa }(1 \%) \text { hipidiomórficos a idiomórficos } \\
\text { con largo max } 0,1 \mathrm{~mm} \text {. Vesiculas } 35 \% \text { alargadas }\end{array}$ & Bomba Vesicular & Sabana Redonda \\
\hline$C-25-3-27.45$ & $\begin{array}{l}515328 \mathrm{E} \\
251361 \mathrm{~N}\end{array}$ & $\begin{array}{l}\text { Textura hipocristalina porfirítica seriada. Ma- } \\
\text { triz: } 75 \% \text { Textura intersertal, microlitos de pla- } \\
\text { gioclasas en una red irregular. Fenocristales: } \\
(25 \%) \text { Plagioclasas }(20 \%) \text { hipidiomórficas a } \\
\text { xenomórficas } 3 \times 1,6 \mathrm{~mm} \text {. Olivinos: }(3 \%) \text {, en } \\
\text { fenocristales hipdiomórficos a xenomórficos con } \\
\text { iddingzita. Clinopiroxeno }(2 \%) \text { idiomórficos }\end{array}$ & Andesita & $\begin{array}{l}\text { Unid. Von Frant- } \\
\text { zius }\end{array}$ \\
\hline VP & $\begin{array}{l}511506 \mathrm{E} \\
242019 \mathrm{~N}\end{array}$ & $\begin{array}{l}\text { Textura holocristalina hipidiomórfica porfirítica. Ma- } \\
\text { triz }(60 \%) \text { intergranular microlitos de plagioclasa y } \\
\text { augitas. Fenocristales }(40 \%) \text {. Plagioclasa (30\%) id- } \\
\text { iomórficos e hipidiomórficos } 15 \mathrm{~mm} \text {. Augitas (4\%) } \\
\text { idiomórficos } 10 \mathrm{~mm} \text {. Magnetita (5\%) hipidiomórfi- } \\
\text { cos. Olivino (1\%) xenomórficos e hipidiomórficos. }\end{array}$ & Andesita & $\begin{array}{l}\text { Unid. Cima Poás } \\
\text { (Cráter Principal) }\end{array}$ \\
\hline PO-13-8-9-1 & $\begin{array}{l}514538 \mathrm{E} \\
251368 \mathrm{~N}\end{array}$ & $\begin{array}{l}\text { Textura hipocristalina-porfirítica. Matriz (97\%) } \\
\text { Textura hialina de aspecto fluidal. Fenocristales: } 3 \\
\% \text { en cumulitos. Plagioclasas: }(1 \%) \text { idiomórficas. } \\
\text { Clinopiroxeno(1\%), hipidiomórfico, magnetita }(1 \%)\end{array}$ & Andesita & $\begin{array}{l}\text { Unid. Cerro } \\
\text { Congo }\end{array}$ \\
\hline
\end{tabular}


El presente estudio proporciona una caracterización geoquímica y petrográfica de las diferentes unidades geológicas del Poás. Se utilizó el diagrama de variación de Peccerillo \& Taylor (1976) que grafica $\mathrm{SiO}_{2}$ vs. $\mathrm{K}_{2} \mathrm{O}$ y que es comúnmente utilizado para rocas volcánicas de arco de islas saturadas en sílice, para realizar una clasificación de las muestras. Las diferentes bases de datos (geoquímica-geocronología-petrografía) recopiladas para este trabajo se encuentran disponibles a través del repositorio de la Revista Geológica de América Central (ver cibersitio http://www.geologia.ucr.ac.cr/revista/pdf_frameset.html).

\section{ESTRATIGRAFÍA}

Los depósitos antiguos de la Cordillera Central fueron agrupados por Alvarado (1984) dentro de la unidad Zurquí-Palmira. Sin embargo, Alvarado (1985) reconoce por primera vez la unidad "Paleo Poás" en el mapa e informe del P.H. Toro II. Soto (1994) propone que el macizo del volcán Poás al igual que el resto de volcanes de la CVC se ha formado por el subsecuente apilamiento de rocas volcánicas durante al menos tres etapas principales a lo largo de casi un millón de años: Protocordillera, Paleocordillera y Neocordillera. En este trabajo, estas fases temporales serán llamadas Proto Poás, Paleo Poás y Neo Poás respectivamente por estar enfocado en los productos originados por el volcán Poás. Dentro del área de estudio no se encontraron afloramientos de unidades que puedan pertenecer a la fase Proto Poás y como se discutirá más adelante proponemos que las unidad litológicas Paleo Poás y Neo Poás propuestas por Soto (1999) pasen a llamarse Unidad Andesitas La Paz y Unidad Cima Poás respectivamente. Se presenta un mapa simplificado del volcán Poás (Fig. 1) y las litologías de las dos últimas fases temporales de construcción del macizo (Paleo y Neo Poás), sin tomar en cuenta las coberturas de piroclastos que cubren el volcán, con el fin de facilitar la comprensión y mostrar de forma más clara la distribución geográfica de las unidades. Asimismo, se realizó un esquema estratigráfico (Fig. 2) donde se ubican las unidades según su posición geográfica con respecto al cráter principal. Las formaciones y unidades estudiadas se describen a continuación.

\section{Unidad Río Sarapiquí}

Denominada así por Soto (1999), ya que aflora únicamente en el cauce del río Sarapiquí y sus tributarios. No debe confundirse con las lavas del Arco de Sarapiquí (Mioceno, Gazel et al., 2005), ya que existen diferencias en edad, geoquímica y posición geográfica. Forma el basamento local de la parte norte y noreste del macizo (Fig. 1). Existen sitios donde esta unidad está sobreyacida por la Unidad Andesitas La Paz y aluviones recientes (Fig. 2).

Está constituida mayoritariamente por brechas y depósitos de flujo piroclástico, así como epiclastos y lavas subordinadas interdigitadas. Las lavas predominantes son andesitas basálticas con piroxenos y olivino subordinado. Con base en perforaciones y lo observado en el cañón del Río Sarapiquí, esta unidad cuenta con un espesor mínimo de $50 \mathrm{~m}$. No existen aún dataciones radiométricas de esta unidad, pero está sobreyacida por la Unidad Andesitas La Paz, datada en 0,6 Ma (Gans com. pers., 2004), mediante $\left({ }^{40} \mathrm{Ar} /{ }^{39} \mathrm{Ar}\right.$ ), por lo que se podría especular que esta unidad probablemente tenga una edad de 0,6-0,7 Ma. También, Soto et al. (2008) sugieren que si la ignimbrita que sobreyace esta unidad es la ignimbrita de la Formación Tiribí datada en 0,322 Ma (Pérez et al., 2006), los materiales de la Unidad Río Sarapiquí podrían llegar a tener una edad de hasta $\sim 0,5 \mathrm{Ma}$. Aún debe aclararse si esta ignimbrita es de Tiribí o alguna otra más antigua (Puente de Mulas, de aprox. 0,5 Ma). Los centros de emisión de esta unidad no han podido ser inferidos, pero se sugiere que podrían pertenecer a la Paleocordillera Central, en tanto que el gradiente del techo se inclina hacia el norte (Soto, 1999).

\section{Formación Colima}

Williams (1952) nomina esta unidad primeramente como Lavas Intracañón. Sin embargo, Fernández (1969) utiliza el nombre de 


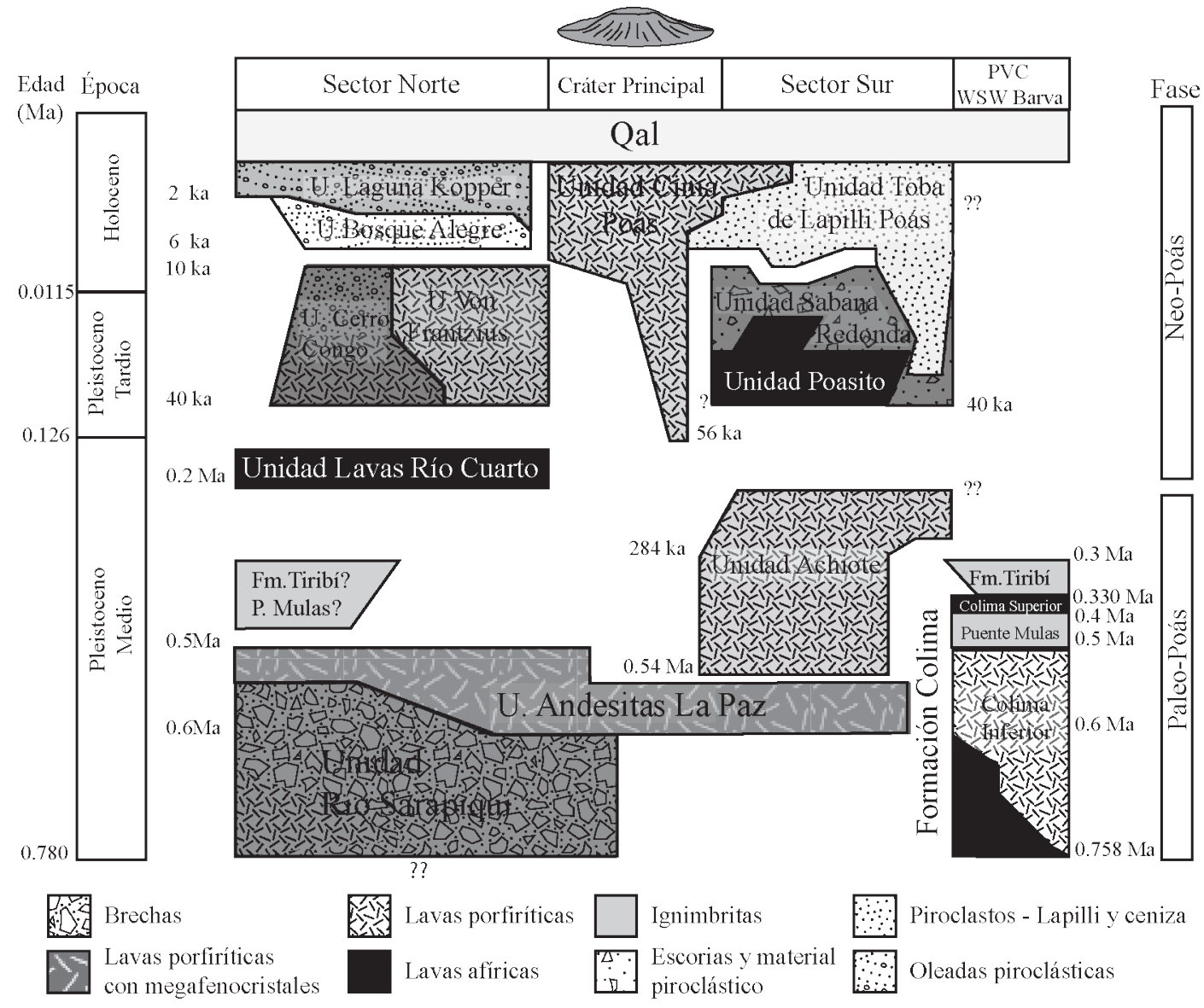

PVC: Piso del Valle Central

Fig. 2: Esquema cronoestratigráfico de las unidades litológicas. Se presenta la litología predominante y subordinada en cada unidad, así como su posición geográfica, ya sea al norte o al sur del cráter principal.

Formación Colima que se mantiene hasta la fecha. Corresponde con el basamento local de la parte sur de la zona de estudio (Fig. 1), sobreyacido por la ignimbrita de la Formación Tiribí. Está compuesta por tres miembros: Colima Inferior, Puente de Mulas y Colima Superior (Fig. 2). De acuerdo con datos calculados con base en pozos de agua de la zona de estudio (Campos et al., 2004), el espesor promedio de la Formación Colima es de $\sim 100 \mathrm{~m}$ (50 m para el miembro inferior, 20 $\mathrm{m}$ para Puente de Mulas y $30 \mathrm{~m}$ para el miembro superior). Colima Inferior está compuesta principalmente por lavas porfiríticas con fenocristales de plag $+\mathrm{cpx}+\mathrm{opx} \pm \mathrm{ol}$ en una matriz con textura intersertal. El miembro intermedio
Puente de Mulas corresponde con un paquete de ignimbritas, aunque en los ríos Tacares y Prendas corresponde con una secuencia de tobitas y sedimentos lacustres (Borgia et al., 1990). Las lavas de Colima Superior tienen textura afírica con solo $4 \%$ de fenocristales dentro de una matriz fluidal y vesículas alargadas. Dataciones radiométricas $\left({ }^{40} \mathrm{Ar} r{ }^{39} \mathrm{Ar}\right)$ de Marshall \& Idleman (1999), Marshall et al. (2003), Gans et al. (2002) y Pérez et al. (2006) establecen la edad de esta formación entre $758 \mathrm{ka}$ (Colima Inferior) y $330 \mathrm{ka}$ (Colima Superior; Cuadro 1).

Kussmaul (1988) y Pérez et al. (2006) destacan que la composición química de las lavas de la Formación Colima es diferente de las lavas de los 
estratovolcanes de la CVC y que tiene mayor similitud con la Formación Tiribí. Por esta razón, además de aspectos geomorfológicos y su extensión lateral, se sugiere que estas lavas probablemente son producto de efusiones a lo largo de fisuras con dirección noreste-suroeste hasta este-oeste. Sin embargo Kussmaul (1988) sugiere que estas fracturas se ubicaron dentro del Valle Central (cerca del Virilla), lo cual no es muy probable porque hubieran tenido que escalar la cordillera.

\section{Unidad Andesitas La Paz}

Fue descrita originalmente como Unidad Paleo Poás por Soto (1999) para referirse a los productos antiguos del volcán Poás. Para evitar confusiones con el nombre de la fase temporal Paleo Poás (Fig 2.), en el presente trabajo se le asigna el nombre de Unidad Andesitas La Paz debido a que en el sector norte de la zona de estudio, existe un afloramiento característico de esta unidad y está localizado en las inmediaciones de la catarata de la Paz y consiste en andesitas porfiríticas con megafenocristales de plagioclasa, que llegan a tener tamaños de $2-3 \mathrm{~cm}$ de largo. Esta unidad aflora tanto al norte como al sur de la zona de estudio (Fig. 1). En el sector norte sobreyacen discordantemente a la Unidad Río Sarapiquí y subyacen los productos emitidos por el Cerro Congo y Von Frantzius. En el sector sur, esta unidad aflora en el Río Poás, al este de San Pedro de Poás, donde también son características las lavas con megafenocristales de plagioclasa muy similares a las que se observan en la zona de la catarata de la Paz. En este sector se encuentra sobreyaciendo a la formación Colima, mientras subyace a la Unidad Achiote aunque existen lavas de esta unidad que son contemporáneas con la Unidad Andesitas La Paz (Fig. 2).

Se compone mayoritariamente de lavas, así como brechas, tobas y epiclastos interdigitados. La composición de las lavas varía de andesitas basálticas con uno o dos piroxenos hasta basaltos, siendo las primeras las más comunes. En uno de los conos piroclásticos de Sabana Redonda aparecen inclusiones que pueden ser correlacionadas con la Andesitas La Paz: una muestra descrita por
Gazel \& Ruiz (2005) presenta características muy particulares, como su textura fanerítica-porfirítica con megafenocristales de plag $+\mathrm{ol}+\mathrm{cpx}+\mathrm{mt}$, en una matriz fina.

Una de las perforaciones realizadas por el ICE para el proyecto Cariblanco sobre esta unidad, muestrea siete flujos de lava, separados por paleosuelos que juntos forman un paquete de 260 $\mathrm{m}$ de espesor.

Siete dataciones radiométricas ${ }^{40} \mathrm{Ar} /{ }^{39} \mathrm{Ar}$, en el sector norte del macizo (Gans, com. pers., 2004) ponen a esta unidad en un rango de edades de entre 0,6 y 0,5 Ma (Cuadro 1). Aunque en el sector sur esta unidad aún no ha sido datada, se especula que en esta zona debe de estar en ese mismo rango de edades. Por la disposición geográfica de los productos pertenecientes a esta unidad, se sugiere que fueron emitidos desde varios sectores en la periferia de la parte central de la zona de estudio, relativamente cerca al actual cráter activo.

\section{Formación Tiribí}

Originalmente llamada Depósitos de Avalancha Ardiente por Williams (1952), Fernández (1969) utilizó el nombre de Formación Tiribí, que se mantiene hasta la fecha. Consiste con una capa de pómez basal con un espesor máximo de $3 \mathrm{~m}$ (la llamada Capa Tibás), seguido por un depósito de ignimbritas con diferentes facies. Aflora principalmente en el flanco sur del volcán Poás, aunque se han encontrado afloramientos aislados en la parte norte que se correlacionan geoquímicamente con esta formación. Los afloramientos de la parte norte están restringidos a la intersección de los ríos María Aguilar y Sarapiquí, aproximadamente a un kilómetro de distancia del escarpe de la falla San Miguel (Fig. 1). Pese a su limitada distribución en la zona norte del área de estudio, Soto (1999) y Soto et al. (2008) han logrado encontrar correlaciones litológicas y químicas con las ignimbritas de la parte sur. En el sector meridional del volcán Poás, esta formación aflora a lo largo de varios cañones de ríos como el Rosales, Poás en varios sitios cerca del escarpe de Alajuela, especialmente en tajos (Echandi, 1981; Borgia et al., 1991; Campos et al., 2004). 
En el sector norte sobreyace a la Unidad Río Sarapiquí y Andesitas La Paz, mientras que en el sector sur sobreyace a la Formación Colima Superior (Fig. 2). En ambos sectores del área de estudio se encuentra aparentemente también por debajo de la unidad Andesitas La Paz. Es posible que las fallas inversas de Alajuela y San Miguel ocasionen que la secuencia se repita y aparentemente esté Tiribí bajo la Unidad Andesitas La Paz. Otra posibilidad es que al ser productos de flujo que viajan preferencialmente por los cañones de los ríos, se hayan depositado allí entre dos unidades de mayor edad, en contacto lateral. La otra posibilidad es que lo que se interpreta como Tiribí en el norte, sea una unidad más antigua, como el Miembro Puente de Mulas. Faltan dataciones radiométricas en ese sector, para dilucidar el problema.

En el sector norte, su espesor se limita a afloramientos de tamaño métrico, mientras que en la parte sur su espesor puede llegar hasta $40 \mathrm{~m}$ (Campos et al., 2004). Las dataciones radiométricas más recientes realizadas por Pérez et al. (2006) son $322 \pm 2$ ka (Cuadro 1). Pérez (2000) y Pérez et al. (2006) interpreta que las ignimbritas de esta formación provienen de la cima del volcán Barva en una explosión que originó la caldera mayor del Barva.

\section{Unidad Achiote}

El nombre de esta unidad se utiliza por primera vez en Campos et al. (2004), posteriormente por Gazel \& Ruiz (2005) y Montes (2007). Aflora únicamente en el sector sur de la zona de estudio (Fig. 1), principalmente al oeste del Río Achiote, donde se encuentran los mejores afloramientos en forma de coladas masivas con espesores máximos de 15 m. También, en el pozo de agua NA-440 (508450 E - $233100 \mathrm{~N}$ ) se observa un espesor para esta unidad de $110 \mathrm{~m}$. El espesor total se podría estimar en varios cientos de metros si se lograra medir desde su base cerca del escarpe de la Falla de Alajuela y el sector cercano a la cúspide del volcán. Esta unidad es concordante y puede llegar a sobreyacer en algunos sectores a las unidades Andesitas La Paz y Tiribí. Subyace de forma irregular las unidades Poasito y Sabana Redonda (Fig. 2).

Consiste en un conjunto de coladas de lava andesíticas y basálticas. Se caracterizan por su fábrica masiva, presentar tanto fracturación en lajas como bloques métricos, producto de enfriamiento. Macroscópicamente, no se pueden diferenciar bien las diferentes coladas de lava, debido a su variación en los porcentajes de fenocristales visibles, estructuras y estados de meteorización, lo que significa que no hay un tipo de lava que sea típico para esta unidad. Son de color gris claro y presentan textura afaníticaporfirítica con fenocristales de plagioclasa centimétricos y algunos ortopiroxenos milimétricos. Microscópicamente presentan textura hipocristalina porfirítica seriada con matriz intersertal hasta levemente hialopilítica, con fenocristales de plag (15-20\%) idiomórficas a hipidiomórficas con un largo máximo de $1 \mathrm{~cm}$, cpx $(9 \%)$ hipidiomórficos con un largo máximo de $1,5 \mathrm{~mm}$, opx (2\%) hipidiomórficos con largo máximo de $3 \mathrm{~mm}$ y ol (1-3\%) idiomórficos a hipidiomórficos con largo máximo de $0,3 \mathrm{~mm}$.

Dos nuevas dataciones radiométricas ${ }^{40} \mathrm{Ar} /{ }^{39} \mathrm{Ar}$ de esta unidad la colocan en un rango de edad entre 538-283 \pm 15 ka (Cuadro 1). La edad máxima de $538 \pm 15 \mathrm{ka}$, la coloca dentro de la fase temporal Paleo Poás y contemporánea con la Unidad Andesitas La Paz. Sin embargo, como se discutirá más adelante las características geoquímicas son diferentes entre estas dos unidades. La geomorfología que presentan las lavas más jóvenes de Achiote (283 -200? ka) (Fig. 1), es muy similar a la presentada por la Unidad Andesitas La Paz superior (500 ka). Planteamos la posibilidad de que debido a su posición geográfica y la dirección preferencial del viento (NE-SW), la lluvia ácida proveniente de la cumbre del volcán haya alterado y erosionado con mayor velocidad las rocas de esta unidad, dejando una morfología similar a la de la Unidad Andesitas La Paz $200 \mathrm{ka}$ años más viejas y que por su posición geográfica no está tan expuesta a la lluvia ácida como sí lo están las de Achiote. Los productos de esta unidad probablemente provienen de focos eruptivos cercanos a la actual cúspide del volcán Poás. 


\section{Unidad Lavas Río Cuarto}

En este trabajo se define por primera vez esta unidad. Se le asigna este nombre ya que las lavas constituyentes afloran principalmente en los alrededores del pueblo de Río Cuarto, extendiéndose con una leve pendiente que baja hacia el norte (Fig. 1). El origen de los productos volcánicos de esta unidad no está asociado con los productos emitidos por la explosión del maar que se ubica en esta zona y que también es conocido como Laguna de Río Cuarto. Como se discutirá más adelante, en este trabajo los depósitos del maar de Río Cuarto serán llamados con el nombre de Unidad Laguna Kopper.

Los principales afloramientos de estas lavas masivas están localizados en tajos artesanales alrededor de la Laguna Río Cuarto, así como cortes de camino y algunas quebradas de la zona. En uno de los tajos artesanales de la zona se logró observar un espesor de $\sim 15 \mathrm{~m}$ de lavas masivas bajo los depósitos maáricos.

Está compuesta por coladas de tipo andesitas basálticas. Macroscópicamente son de color gris oscuro, tienen textura afanítica fluidal, con algunos fenocristales visibles (3\%) de plagioclasa de tamaño milimétrico. Microscópicamente, presentan una textura holocristalina con cristales milimétricos de plag $+\mathrm{cpx} \pm$ ol. Se observan estructuras de flujo como pliegues y una dirección preferencial en el eje largo de los fenocristales de plagioclasas y de la matriz. En algunos casos se observan las plagioclasas de la matriz bordeando a plagioclasas de mayor tamaño (Cuadro 2).

Estratigráficamente se encuentra sobreyaciendo a la Unidad Andesitas La Paz y subyace a la Unidad Congo y la Unidad Laguna Kopper (Fig. 2). Dos muestras de las lavas que afloran cerca de la laguna Kopper o Río Cuarto fueron datadas radiométricamente con ${ }^{40} \mathrm{Ar} /{ }^{39} \mathrm{Ar}$ por Carr et al. (2007), dando ambas una edad de $201 \pm 30 \mathrm{ka}$ (Cuadro 1). El origen de esta unidad se atribuye a los focos volcánicos en la fase temporal Paleo Poás tardía o bien la Neo Poás temprana. Por las características petrográficas que presentan estas lavas y lo lejos que se encuentran del actual cráter principal, se puede hipotetizar que se originaron en un vulcanismo fisural.

\section{Unidad Poasito}

Igual que la unidad anterior, este nombre se utiliza por primera vez en Campos et al. (2004). Posteriormente, Gazel \& Ruiz (2005) llaman Andesitas Poasito a las lavas de textura afírica que afloran en la zona entre los poblados de Poasito, Sabana Redonda, Bajos del Tigre y hasta Los Ángeles. Estas lavas únicamente están presentes en el sector sur de la zona de estudio y afloran principalmente en los cañones del los ríos Poás, Mastate, Poasito y Prendas (Fig. 1).

Las coladas de lava que constituyen esta unidad son masivas, con texturas fluidales mostrando pliegues y fallas inversas, además estructuras de cizalle interno características que quedan como remanente del movimiento de la colada.

Esta unidad se encuentra sobreyaciendo discordantemente a la Unidad Achiote y podría llegar a ser contemporánea con la Unidad Sabana Redonda o subyacerla en algunos sectores (Fig. 2). Su espesor observado es de unos $20 \mathrm{~m}$ en el río Poasito, aunque en perforaciones del área se observan espesores de hasta $80 \mathrm{~m}$ (Gazel \& Ruiz, 2005).

Macroscópicamente, el color de estas lavas en las superficies sanas varía de gris claro a oscuro dependiendo del contenido de vidrio. La textura es afanítica-fluidal con pocos cristales milimétricos de plagioclasa y piroxenos en una matriz vítrea. Microscópicamente, se caracteriza por presentar una textura hipocristalina-porfirítica, con matriz hialina de aspecto fluidal y un contenido de fenocristales hipidiomórficos que no supera el $5 \%$, de plagioclasa, clinopiroxeno y ortopiroxenos (Cuadro 2).

No existen dataciones radiométricas de esta unidad, no obstante se especula, con base en su posición estratigráfica, que podría tener una edad entre 40 ka y $25 \mathrm{ka}$. Las características petrográficas y reológicas y la localización de la fuente de estas coladas dentro de la fractura volcanotectónica del Poás, sugieren que se originaron por medio de un volcanismo fisural en el flanco sur del volcán (Prosser \& Carr, 1987; Gazel \& Ruiz, 2005). 


\section{Unidad Sabana Redonda}

Se encuentra ubicada en el sector sur de la zona de estudio y corresponde con los depósitos de los conos piroclásticos del mismo nombre. Los mejores afloramientos se localizan en los tajos Rocha, Cahrmi, Poás, Poasito y Los Mora. Otros sitios donde aflora son los viveros de Bajos del Tigre y en los cortes de carretera entre las poblaciones de Sabana Redonda y Poasito (Gazel \& Ruiz, 2005; Fig. 1). Los depósitos de esta unidad, sobreyacen a las unidades Achiote y Poasito, mientras que por encima de ella se encuentran piroclastos de la unidad Toba de Lapilli Poás definida por Prosser (1983) (Fig. 2). Los espesores alcanzan hasta $60 \mathrm{~m}$ en las localidades cercanas a los puntos de emisión (Gazel \& Ruiz, 2005).

Esta unidad está compuesta por depósitos de bombas y bloques en una matriz de lapilli, niveles de aglomerados y pequeñas seudocoladas de lava clastogénicas en la base. Estos depósitos presentan una estratificación poco evidente y una selección de mala a moderada, la cual mejora al alejarse de la fuente. En varios sitios se pueden apreciar estructuras verticales que se interpretan como conductos volcánicos o posibles chimeneas de desgasificación (Gazel \& Ruiz, 2005).

Los fragmentos juveniles corresponden principalmente con bombas escoriáceas tipo fusiforme, corteza de pan e irregulares de hasta 2 $\mathrm{m}$ de largo. Con menos frecuencia se encuentran bloques angulares de lavas preexistentes de las unidades Poasito, Achiote y Andesitas La Paz. Los componentes juveniles presentan coloración naranja oscuro, producto de una oxidación de hierro a alta temperatura, al entrar en contacto con el aire. También se encuentran niveles subordinados de un color gris claro, que sugiere condiciones ambientales relativamente secas que no favorecieron la oxidación del material (cf. Fisher \& Schminke, 1984).

Las bombas presentan 30-35 \% de vesículas, en una matriz vítrea con una textura fluidal similar a las lavas de la Unidad Poasito (Cuadro 2). Las seudocoladas de lava presentan un color gris y una textura afírica-fluidal también similar a las lavas de la unidad Poasito con espesores máximos de $4 \mathrm{~m}$. Estas seudocoladas de lavas se encuentran intercaladas en los niveles basales de los conos piroclásticos en los tajos Cahrmi y Rocha y probablemente representen coladas de aglutinados que se soldaron a altas temperaturas.

Con base en una datación radiométrica con $14 \mathrm{C}$ realizada en material carbonizado por los depósitos de los conos de los alrededores de la localidad de Sabana Redonda se obtuvo una edad calibrada (Van der Plicht et al. 2004) de 40,04 + 1,37-2,40 ka (Cuadro 1). Sin embargo, consideramos que pueden existir diferencias de edad entre los conos de al menos $10 \mathrm{ka}$. La fuente de emisión de esta unidad corresponde con un alineamiento norte-sur de al menos 5 a 6 conos piroclásticos, desde el hito Carlos hasta el sector de Sabana Redonda (Fig. 1).

\section{Unidad Cerro Congo}

El volcán Cerro Congo es un estratocono poco conocido debido a su difícil acceso y densa cobertura vegetal. Se ubica en el sector norte de la zona de estudio, entre el volcán Von Frantzius y la depresión de Bosque Alegre (Fig. 1). Se trata de un cono bien desarrollado hacia el norte y cubierto hacia el sur por las lavas emitidas del cono Von Frantzius. Estratigráficamente, esta unidad subyace a la unidad Von Frantzius, aunque también podría ser contemporánea con algunas de las lavas más viejas de este cono (Fig. 2).

Soto (1999) subdivide esta unidad en tres subunidades: 1) Congo inferior, donde agrupa la mayor parte de depósitos lávicos proximales del Congo (basaltos porfiríticos compuestos por plag+ ol \pm cpx); 2) Congo Superior en el sector noreste y hasta el maar de Hule, donde se encuentran lavas andesítico-basálticas, algunas porfiríticas y otras con textura afírica, removidas y expulsadas en parte durante la formación del maar, en cuyas paredes en el sector sur se pueden observar hasta dos coladas de lava separadas por epiclastos (un espesor de hasta $60 \mathrm{~m}$ ) y 3) Congo Distal, donde se incluye la cobertura de epiclastos y piroclastos de flujo, especialmente en los ríos María Aguilar y Sardinal, donde aflora un espeso depósito de lodo que contiene numerosas bombas de una lava vítrea (basalto), de tamaño centimétricos a métrico, 
interpretado como un enorme lahar originado simultáneamente durante la erupción que formó las bombas contenidas. Este depósito lahárico es en parte sobreyacido por lavas de composición similar de la subunidad Congo Inferior.

El volcán Cerro Congo no conserva un cráter bien definido, sino que presenta dos herraduras abiertas hacia el NNW y al NNE. Después de haber observado las consecuencias erosivas que sufrió este cono después del Terremoto de Cinchona del 2009, se podría especular que estas cárcavas corresponden con un fenómeno erosivo que se ha amplificado y repetido durante miles de años en eventos sísmicos anteriores.

Con base en una datación radiométrica con 14C realizada por (Malavassi et al. 1990), y calibrada en este trabajo usando el método de Van der Plicht et al. (2004) se obtuvo una edad de 35,6 $\pm 0,6 \mathrm{ka}$ (Cuadro 1) para Congo Inferior, aunque podría llegar hasta ser casi contemporánea con los depósitos más recientes de Von Frantzius.

\section{Unidad Von Frantzius}

Prosser \& Carr (1987) estudiaron las lavas emitidas por el cono Von Frantzius, pero es Soto (1999) quien utiliza este nombre para esta unidad que se ubica al norte del cráter principal (Fig. 1). Estratigráficamente se encuentra por encima de las lavas de la Unidad Andesitas La Paz y es sobreyacida por la Unidad Bosque Alegre (Fig. 2). En una perforación realizada por el ICE para el proyecto hidroeléctrico Cariblanco se observó un espesor máximo de $70 \mathrm{~m}$ para las lavas distales de esta unidad.

Está compuesta principalmente por flujos de lava interdigitados con brechas y epiclastos y sobreyacidos por delgados depósitos epiclásticos y piroclásticos. Según Soto (1999), hay cinco campos de coladas de lavas superpuestos: el más antiguo se ubica del lado noroeste del volcán, luego las lavas Cariblanco compuestas por tres campos de coladas que afloran hacia el noreste y por último las lavas Ángel que afloran al sur del caserío de Cariblanco. Las lavas Ángel tienen una textura porfirítica ( $70 \%$ de cristales) con olivino en conjuntos glomeroporfiríticos (plag $+\mathrm{opx}+\mathrm{ol} \pm \mathrm{cpx}$ ).
Las lavas Cariblanco son andesitas basálticas con dos piroxenos y olivino subordinado y presentan $40 \%$ de cristales.

Una datación de ${ }^{40} \mathrm{Ar} /{ }^{39} \mathrm{Ar}$ realizada en la parte basal distal de esta unidad da una edad de $41 \mathrm{ka}$ (Gans, com. pers., 2004; Cuadro 1). Además, se hicieron tres dataciones radiométricas en lahares que subyacen a estas lavas en su extremo noreste, cerca de Cariblanco, cuyas edades de radiocarbono dieron mayores a 42400 años, y una vez calibradas, > 46600 años. Por lo tanto, Von Frantzius tendría una edad máxima de 46,60 ka (Cuadro 1). Soto (1999) estima que las últimas coladas del Von Frantzius podrían tener una edad mínima de $10 \mathrm{ka}$, y por lo tanto este volcán se habría desarrollado entre $\sim 47$ y $10 \mathrm{ka}$.

\section{Unidad Cima Poás (Cráter Principal y Botos)}

Soto (1999) utilizó el nombre Neo Poás para referirse a esta unidad. Sin embargo, en el presente estudio se utiliza ese nombre solamente para referirse a la fase temporal y en su lugar se utiliza el nombre Cima Poás para los productos que han sido emitidos de los cráteres Botos y Principal del Poás (Fig. 1). Los productos del cráter Principal se extienden hacia el oeste, mientras que las coladas emitidas por el cráter Botos se extienden hacia el este y afloran sobre una secuencia considerable de piroclastos indiferenciados en la quebrada Pulga (Fig. 2).

De acuerdo con Soto (1999), las lavas provenientes de Botos rellenan principalmente el piso de la cúspide del Poás y están limitadas por escarpes de fallas. Una de las fallas que limita esta unidad unos $5 \mathrm{~km}$ al este del cráter Botos (la Falla Ángel) fue la causante del terremoto de Cinchona en enero del 2009 (RSN, 2009). Estas lavas corresponden principalmente con basaltos y andesitas basálticas (Prosser \& Carr 1987; Cigolini et al., 1991; Malavassi, 1991). Prosser \& Carr (1987) dataron radiométricamente $\left({ }^{14} \mathrm{C}\right)$ una erupción en $7540 \pm 100$ años, y posteriormente Soto (1999), utilizando el programa de Stuiver \& Reimer (1993) obtiene la edad calibrada de 8330 +70-160 años a.P. Una nueva datación radiométrica ${ }^{40} \mathrm{Ar} /{ }^{39} \mathrm{Ar}$ para las lavas distales de Botos que 
afloran en el sector este del cráter dio como resultado $56 \pm 0,04 \mathrm{ka}$ (Cuadro 1). Especulamos que la edad de las lavas emitidas por el cráter Principal podrían ser contemporáneas y más jóvenes que las lavas de Botos.

Según Prosser \& Carr (1987), los depósitos del cráter Principal corresponden en su mayoría con piroclastos distribuidos alrededor del cráter. Documentan tres eventos de colapso interno del cráter, lo cual habría ocurrido posteriormente al cese eruptivo del cono Botos. Además, identifican tres flujos de lava que posiblemente fueron eruptados del cráter hacia el norte y noroeste.

\section{Unidad Bosque Alegre}

Definida por Soto (1999), quien dentro de ella incluye los productos emitidos por el maar de Hule y el cráter de explosión Pata de Gallo, también conocido como Los Ángeles. Además, dentro de esta unidad se incluyen los materiales originados por dos conos intramaáricos, los cuales están muy cerca uno del otro y dan la apariencia de ser uno solo. Aflora al norte del volcán Congo, en el sector norte de la zona de estudio (Fig. 1). Estratigráficamente sobreyace a los productos de los volcanes Congo y Von Frantzius (Fig. 2).

Los productos de esta unidad son mayoritariamente piroclásticos (oleadas, flujo y caída), así como un pequeño campo de lava intramaárica que proviene de los dos conitos, los cuales también emitieron piroclastos. Las lavas de los conos intramaáricos son basaltos con olivino, con un contenido de sílice entre 50-51\% (Tournon, 1984; Prosser \& Carr, 1987; Malavassi, 1991).

Malavassi et al. (1990) habían datado eventos del maar con 14C que una vez calibradas por Soto (1999) con el programa de Stuiver \& Reimer (1993) obtuvo 2790 $\pm 70-20$ años a.P. Sin embargo, Salani \& Alvarado (2010) con base en levantamientos estratigráficos, reinterpretación de dataciones y su correlación con piezas arqueológicas concluyen que este maar se formó hace $6,1 \mathrm{ka}$ (Cuadro 1). El cráter de explosión Pata de Gallo sería contemporáneo y genéticamente asociado al maar Laguna Hule.

\section{Unidad Laguna Kopper}

En el presente trabajo se define bajo esta unidad para aquellos depósitos explosivos asociados con el maar de Río Cuarto o Kopper, localizada al norte de la zona de estudio (Fig. 1). Se trata del cráter explosivo también conocido como Laguna de Río Cuarto, pero para evitar confusiones con la Unidad Lavas Río Cuarto, se utiliza el nombre original con el que se conocía a esta laguna. Sus productos afloran en un estrecho eje con dirección este-oeste a partir del cráter explosivo, que se extiende solamente unos kilómetros con espesor variable y que desaparece rápidamente. Estos depósitos localmente sobreyacen en forma discordante las lavas afíricas de la Unidad Lavas de Río Cuarto (Fig. 2). Los depósitos de esta unidad corresponden con tres capas de materiales que se describen a continuación: 1) capa inferior de lapilli con bloques balísticos menores y capas de ceniza de oleadas relativamente ricas en líticos. 2) Capa intermedia compuesta por brecha volcánica con lapilli grueso y bloques andesíticos balísticos de hasta $3 \mathrm{~m}$ de diámetro que provienen de la roca caja. 3) Una secuencia superior compuesta principalmente de capas de caída de lapilli, bloques y pómez. El espesor de este paquete no supera los $15 \mathrm{~m}$. Aún no existen análisis químicos de los materiales emitidos por el cráter de explosión, ni dataciones radiométricas. Sin embargo, se sugiere con base a la geomorfología y piezas arqueológicas que han sido encontradas en sus alrededores, que la edad de este maar sea muy similar o más joven a las obtenidas para el maar de Laguna Hule, probablemente en el rango 3-4 ka (Soto et al., 2010).

\section{Unidad Toba de Lapilli Poás}

Definida por Prosser (1983), quien agrupa las diferentes tobas de lapilli de caída del sector cuspidal del volcán Poás. Posteriormente es analizada y estudiada en Gazel \& Ruiz (2005). Se extiende desde el sector cuspidal de volcán Poás hasta el sector de Grecia, hacia el suroeste, de modo que se encuentra cubriendo las unidades lávicas del 
sector sur del volcán Poás. Gazel \& Ruiz (2005) presentan un mapa de isopletas del tamaño máximo de los lapilli juveniles, donde muestran cómo las partículas de mayor tamaño se ubican cerca de la cúspide y disminuyen su diámetro siguiendo la dirección preferencial del viento NE-SW para esta zona. Para facilitar la comprensión y distribución de las unidades lávicas del sector sur de la zona de estudio, la Unidad Toba de Lapilli Poás no se incluye en el mapa (Fig. 1).

Está compuesta por dos secciones: una inferior que se encuentra sobreyacida por las coladas de la Unidad Poasito y los depósitos de la Unidad Sabana Redonda y que Prosser \& Carr (1987) asignan una edad superior a $40 \mathrm{ka}$ con base en una datación con ${ }^{14} \mathrm{C}$, y una sección superior que posiblemente representa los últimos eventos volcánicos de los cráteres Botos y principal (Fig. 2).

En la zona de Sabana Redonda (al SSE de la cima) y en todo el flanco oriental aflora en cortes de la carretera, los cuales después del Terremoto de Cinchona de enero del 2009, quedaron mejor expuestos y presentan espesores superiores a $7 \mathrm{~m}$. Las tobas y lapilli presentan un color gris claro cuando se encuentran frescos, los colores naranja, café y morado son comunes cuando se encuentran meteorizados.

\section{Unidad fluviales y epiclastos poco consolidados}

Se localizan en varios sectores de la zona de estudio, principalmente en el sector norte, donde representan las facies distales del Congo y los depósitos de piedemonte del escarpe de San Miguel. También se encuentran los sedimentos depositados en el río María Aguilar, particularmente aguas arriba del puente de la carretera principal. Según Soto (1999), esta cuenca pequeña de características más fluviales que lacustres, se originó por el basculamiento y combamiento originado por la falla-pliegue del escarpe de San Miguel, que represó el río y actuó como cuenca de depositación de sedimentos finos volcanoclásticos poco retrabajados. El mismo autor describe como existen una serie de terrazas colgadas adosadas a las paredes del río Sarapiquí, con dos niveles: uno cerca de $120 \mathrm{~m}$ sobre el cauce actual y otro entre los 10 y $50 \mathrm{~m}$ sobre el cauce actual. Litológicamente, muestran una compleja anatomía de lóbulos fluviales intercalados con otros lóbulos de lahares y hasta coluvios, cuyo espesor conjunto alcanza las decenas de metros. Parecen documentar al menos dos períodos de levantamiento intenso y rápido en el sector oriental del macizo volcánico.

\section{GEOQUÍMICA}

Se muestran las relaciones geoquímicas de cada unidad geológica del Poás, así como la variación geoquímica durante la evolución de macizo entre ellas. Geoquímicamente, las lavas de las unidades geológicas del volcán Poás descritas en la sección anterior, varían desde basaltos hasta dacitas. Los tipos de lava más comunes presentes según el diagrama de clasificación de rocas de Peccerillo \& Taylor (1976, Fig 3.) son andesitas basálticas y andesitas. En el mismo diagrama se observa que existen dos tendencias en los valores de $\mathrm{K}_{2} \mathrm{O}$, lo cual permitió diferenciarlas entre calcoalcalinas o calcoalcalinas altas en K. Utilizando el diagrama de variación $\mathrm{TiO}_{2}$ vs. $\mathrm{MgO}$ (Fig. 4) se muestra la diferenciación y mezcla de las unidades geoquímicas, así como su cristalización fraccionada. La variación de contenido de los óxidos mayores $\mathrm{TiO}_{2}, \mathrm{P}_{2} \mathrm{O}_{5}$ y las trazas $\mathrm{Zr}$ y Ba entre cada unidad (Fig. 5), muestra los cambios geoquímicos durante la evolución del macizo. Cada unidad lávica fue asociada a uno de los dos componentes magmáticos del volcán Poás: Uno el Componente Geoquímico Sabana Redonda (CGSR) y el segundo el.Componente Geoquímico Von Frantzius (CGVF) definidos por Gazel \& Ruiz (2005). Los rangos de los principales valores geoquímicos utilizados en los diagramas de cada unidad son presentados en el cuadro 3 .

\section{Unidad Río Sarapiquí}

Según los análisis químicos, las rocas que componen a esta unidad varían desde basaltos hasta andesitas. Todas presentan valores de $\mathrm{K}_{2} \mathrm{O}$ menores 


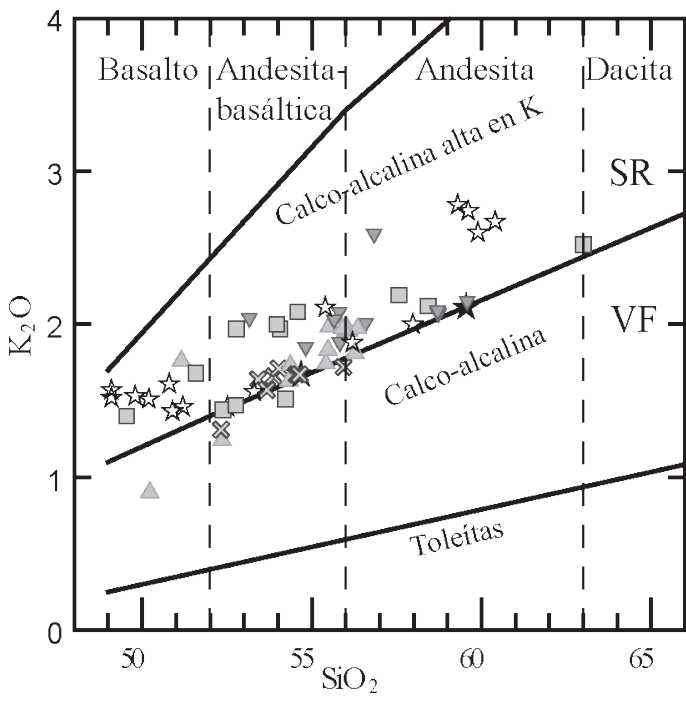

$\mathrm{SR}=$ Componente Geoquímico Sabana Redonda

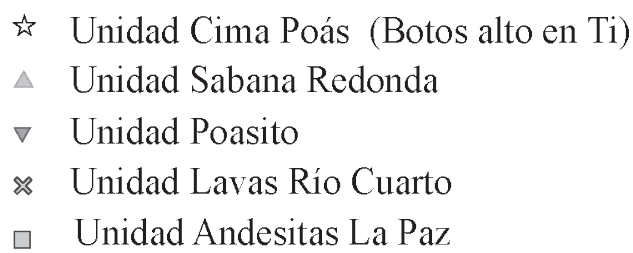

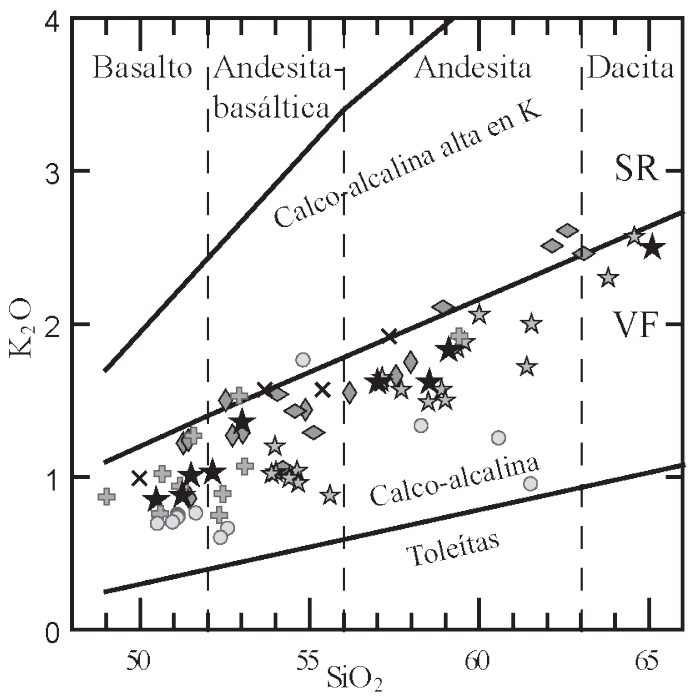

$\mathrm{VF}=$ Componente Geoquímico Von Frantzius

ฟ Unidad Cima Poás (Cráter Principal)

- Unidad Bosque Alegre

* Unidad Cima Poás (Botos bajo en Ti)

$\diamond$ Unidad Von Frantzius

\& Unidad Cerro Congo

$\diamond$ Unidad Achiote

× Unidad Río Sarapiquí

Fig. 3: Diagramas de clasificación de las unidades litológicas del volcán Poás según Peccerillo \& Taylor (1976). Elementos mayores (óxidos) en \%.

a $2 \%$ y se ubican en la zona correspondiente a la serie calcoalcalina con cierta tendencia a ser alta en $\mathrm{K}$, pero sin sobrepasar el límite de valores altos en K (Fig. 3). Presentan valores de $\mathrm{TiO}_{2}<1 \%$ y de $\mathrm{MgO}<\% 5$ (Fig. 4) y los valores de $\mathrm{P}_{2} \mathrm{O}_{5}$ también son relativamente bajos (0,2-0,23 \%; Fig. 5). Esta unidad pertenece al Componente Geoquímico Von Frantzius y geoquímicamente se diferencia bien de la Unidad Andesitas La Paz que la sobreyace.

\section{Unidad Andesitas La Paz}

Desde el punto de vista geoquímico, las rocas de esta unidad varían de basaltos hasta andesitas, aunque la mayoría de las muestras analizadas son andesitas basálticas (Fig. 3), pertenece a la serie calcoalcalina con alto $\mathrm{K}$, aunque algunas muestras presentan valores bajos de $\mathrm{K}$. La mayoría de las muestras presentan valores altos de $\mathrm{TiO}_{2}(\geq 1$ $\%$ ) y valores bajos a intermedios de $\mathrm{MgO}(\leq 5$ $\%)$, con una tendencia por cristalización fraccionada de la fases minerales de olivino, piroxeno plagioclasa y magnetita (Fig. 4), además valores $>$ $0,3 \%$ de $\mathrm{P}_{2} \mathrm{O}_{5}$ y rangos de 600-1000 ppm de Ba y 175-200 ppm de Zr (Fig. 5). Esta unidad pertenece al Componente Geoquímico Sabana Redonda, diferenciándose geoquímicamente de las unidades Río Sarapiquí (subyacente) y Achiote (en un rango de edad similar). 


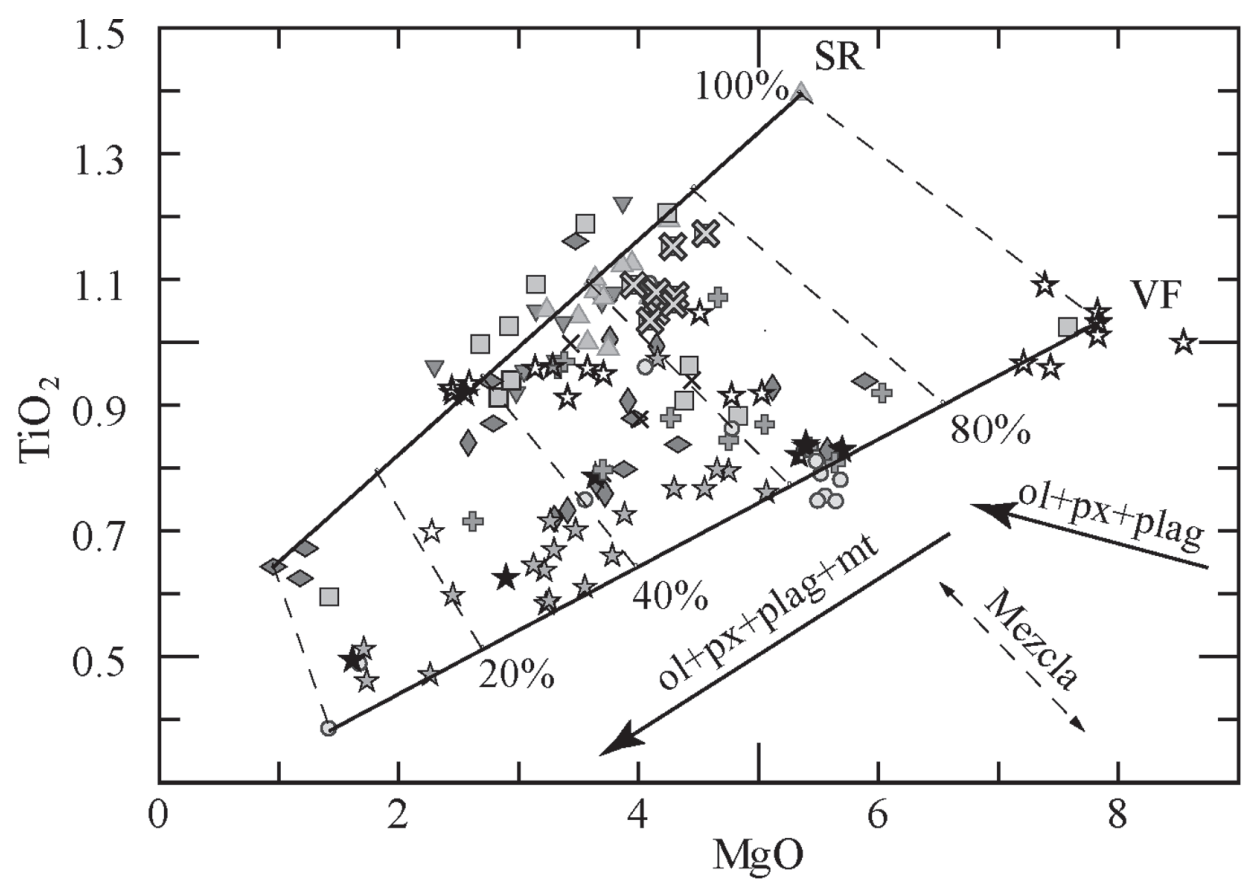

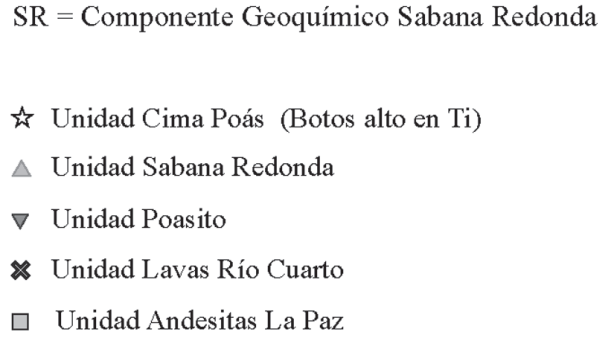

$\mathrm{VF}=$ Componente Geoquímico Von Frantzius

* Unidad Cima Poás (Cráter Principal)

- Unidad Bosque Alegre

* Unidad Cima Poás (Botos bajo en Ti)

- Unidad Von Frantzius

$\$$ Unidad Cerro Congo

$\diamond$ Unidad Achiote

$\times \quad$ Unidad Río Sarapiquí

$\mathrm{Ol}=$ Olivino,$\quad \mathrm{px}=$ Piroxeno,$\quad$ plag $=$ Plagioclasa,$\quad \mathrm{mt}=$ Magnetita

Fig. 4: Diagrama de variación entre los \% de los elementos mayores TiO2 vs MgO. Se muestran los diferentes rangos de las unidades geoquímicas, su diferenciación y mezcla. Los vectores muestran la cristalización fraccionada, mientras que las líneas punteadas los porcentajes de cada componente magmático y sus respectivas mezclas.

\section{Formación Tiribí}

La composición química de esta ignimbrita tiene un rango bastante amplio, donde se encuentran andesitas basálticas y andesitas, pero las rocas traquiandesíticas (según la clasificación TAS son las que predominan, (Pérez et al., 2006). Esta unidad pertenece a la serie calcoalcalina con alto K. La mayoría de las muestras de esta unidad presentan valores altos de $\mathrm{TiO}_{2}(>1 \%)$ y valores bajos de $\mathrm{MgO}(\leq 4 \%)$ y $<0,5$ $\%$ de $\mathrm{P}_{2} \mathrm{O}_{5}$. Proviene del volcán Barva y se diferencia muy bien de las lavas del volcán Poás al comparar los valores de elementos traza como $\mathrm{Sr}$ con rangos entre 200-900 ppm y $\mathrm{Rb}$ con rangos entre 50-150 ppm (Pérez et al., 2006). Por estas razones no se incluye en ninguno de los componentes geoquímicos del Poás. 


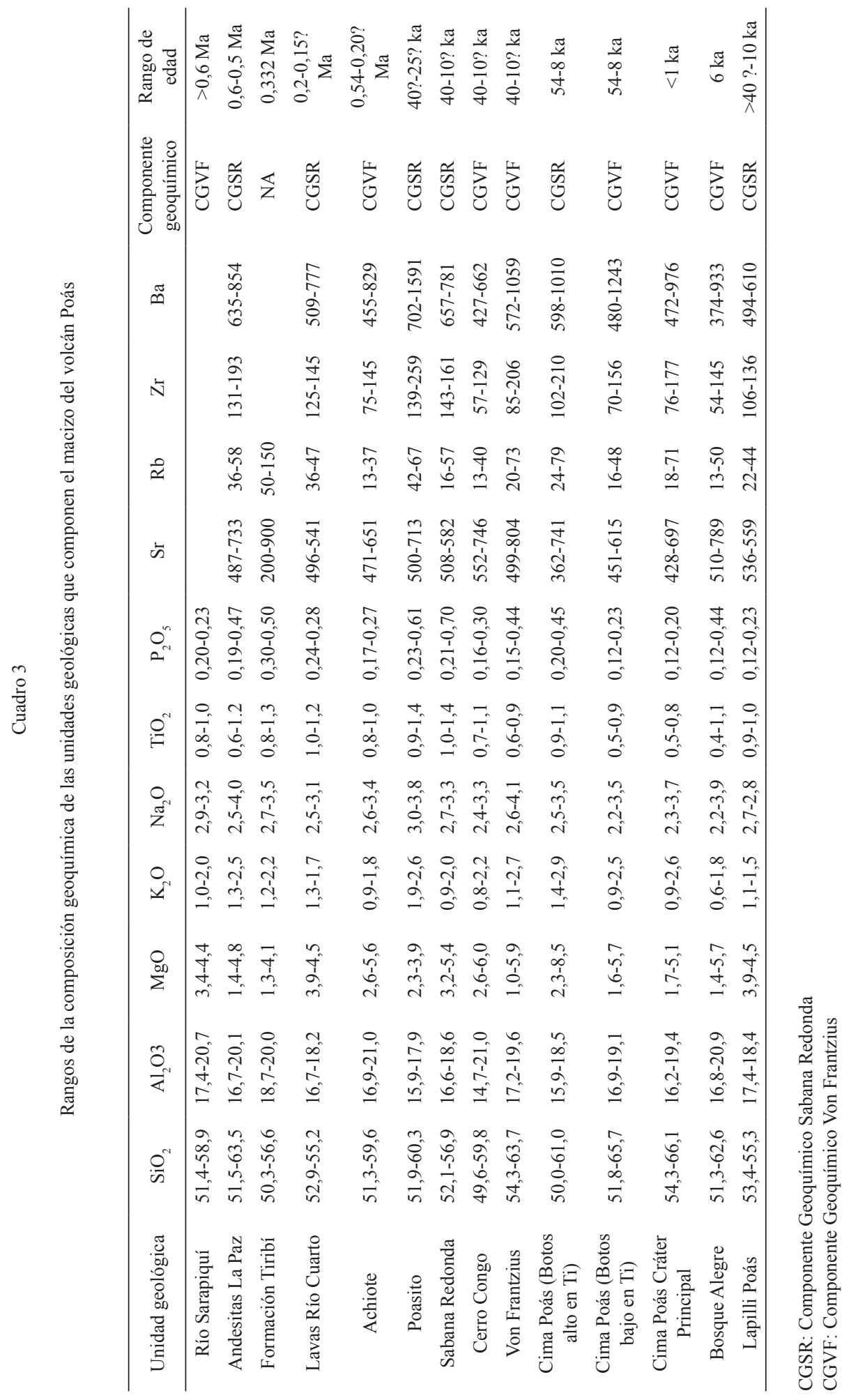




\section{Unidad Lavas Río Cuarto}

Desde el punto de vista geoquímico, esta unidad está compuesta únicamente por andesitas basálticas y pertenecen a la serie calcoalcalina alta en K (Fig. 3). Las lavas de esta unidad presentan valores altos de $\mathrm{TiO}_{2}(\geq 1 \%)$ y valores entre 4 $-5 \%$ de $\mathrm{MgO}$ (Fig. 4) y $0,2-0,3 \%$ de $\mathrm{P}_{2} \mathrm{O}_{5}$, con rangos de 600-800 ppm de Ba y 130-150 ppm de Zr (Fig. 5). Pertenece al Componente Geoquímico Sabana Redonda.

\section{Unidad Achiote}

Esta unidad está compuesta por rocas que varían desde basaltos hasta andesitas, dentro de la serie calcoalcalina baja a normal en K (Fig. 3). Esto representa una diferencia muy significativa con respecto a las muestras de la Unidad Andesitas La Paz y Poasito, que tienden a ser más ricas en $\mathrm{K}_{2} \mathrm{O}$ y que sobreyacen y subyacen respectivamente a la Unidad Achiote. Esta unidad presenta valores $<1 \%$ de $\mathrm{TiO}_{2}$ y bajos a intermedios de $\mathrm{MgO}$ $\left(<5,5 \%\right.$; Fig. 4) y $\mathrm{P}_{2} \mathrm{O}_{5}(<0,3 \%)$, además rangos de 500-600 ppm de Ba y 75-130 ppm de Zr (Fig. 5). Se asocia geoquímicamente a esta unidad con el Componente Geoquímico Von Frantzius.

\section{Unidad Poasito}

Esta unidad pertenece a la serie calcoalcalina alta en $\mathrm{K}$ y varía de andesitas basálticas a andesitas (Fig. 3). Presentan valores $\geq 1 \% \mathrm{de} \mathrm{TiO}_{2}$ (Fig. 4). Como ya habían mencionado Tournon (1984), Prosser \& Carr (1987), Gazel \& Ruiz (2005), en este estudio se comprueba un comportamiento químico muy similar entre estas andesitas afíricas de la Unidad Poasito con las lavas porfiríticas pertenecientes a la Unidad Andesitas La Paz, especialmente en los contenidos de $\mathrm{TiO}_{2}$ y $\mathrm{K}_{2} \mathrm{O}$, sin embargo estas últimas son un poco más evolucionadas. Existe un comportamiento muy diferente con respecto a la Unidad Achiote, la cual no es alta en $\mathrm{K}_{2} \mathrm{O}$ y tiene valores de $\mathrm{TiO}_{2}$ (Fig. 4) y otros elementos mayores un poco más bajos (Fig. 5). Los valores de Zr para esta unidad están en el rango de 150-250 ppm. Mientras que los de $\mathrm{Ba}$ son $>500$ ppm y hasta 1100 ppm (Fig. 5). Esta unidad se asocia con el Componente Geoquímico Sabana Redonda.

\section{Unidad Sabana Redonda}

Desde un punto de vista geoquímico, esta unidad varía de basaltos a andesitas de la serie calcoalcalina alta en K (Fig. 3). Esta unidad muestra los mayores contenidos de $\mathrm{TiO}_{2}$ del Poás (1-1,4 \%), con porcentajes de $\mathrm{MgO}$ de 3 a $4 \%$. (Fig. 4) y valores de $\mathrm{P}_{2} \mathrm{O}_{5}$ de 0,2 a $0,3 \%$. Al igual que la Unidad Andesitas La Paz, Sabana Redonda presenta los valores más altos en $\mathrm{Zr}$ (140-160 ppm), $\mathrm{Nb}(12-17 \mathrm{ppm})$ y valores entre $600-800$ ppm de Ba (Fig. 5). Es con base en la caracterización geoquímica de esta unidad que Gazel \& Ruiz (2005) definen el Componente Geoquímico Sabana Redonda. Geoquímicamente los materiales expulsados de los conos piroclasticos de Sabana Redonda son muy similares a las lavas de la Unidad Poasito Sin embargo las lavas de Poasito son ligeramente más evolucionadas que las lavas más primitivas de la Unidad Sabana Redonda.

\section{Unidad Cerro Congo}

Las muestras de esta unidad varían de basaltos a andesitas de la serie calcoalcalina bajas a normales en K (Fig. 3). El porcentaje de magnesio es variable entre 2 y $6 \%$, pero sus niveles de $\mathrm{TiO}_{2}$ son $<1 \%$ (Fig. 4). Presenta valores entre 0,2- 0,3\% de $\mathrm{P}_{2} \mathrm{O}_{5}$. En elementos traza como $\mathrm{Ba}(400-700 \mathrm{ppm})$, $\mathrm{Nb}$ (5-20 ppm) y Zr (50-200 ppm) (Fig. 5), presenta valores más bajos que las unidades Andesitas $\mathrm{La}$ Paz, Poasito y Sabana Redonda. Está asociada con el Componente Geoquímico Von Frantzius

\section{Unidad Von Frantzius}

Las lavas de esta unidad varían de andesitas basálticas a dacitas, dentro la serie calcoalcalina baja en $\mathrm{K}$, con algunas muestras que tienden a ser normales y hasta altas en K (Fig. 3). Los valores de $\mathrm{K}_{2} \mathrm{O}$ no superan $2,5 \%$, presenta valores de 
$\mathrm{TiO}_{2}<0,8 \%$ y bajos a intermedio de $\mathrm{MgO}$ (1-6 \%) (Fig. 4), mientras que los valores de $\mathrm{P}_{2} \mathrm{O}_{5}$ son $<0,3 \%$. En elementos traza como $\mathrm{Sr}$, presenta valores entre $500-800 \mathrm{ppm}$ y $\mathrm{Rb}$ con rangos entre 20-75 ppm (Fig. 5). Gazel \& Ruiz (2005) definen el Componente Geoquímico Von Frantzius con base en la caracterización de esta unidad.

\section{Unidad Cima Poás (Cráter Principal y Botos)}

Para caracterizar geoquímicamente esta unidad, se subdividió en dos: Unidad Cima Poás Cráter Botos y Cima Poás - Cráter Principal, ya que presentan diferencias químicas muy significativas que se describen a continuación.

\section{Unidad Cima Poás - Cráter Botos}

El comportamiento de esta unidad es bastante heterogéneo, con rocas que varían desde basaltos hasta dacitas. Además hay lavas que son calcoalcalinas altas en $\mathrm{K}$, mientras otras son calcoalcalinas bajas en K (Fig. 3). También son muy variables con respecto al $\mathrm{TiO}_{2}$, pues pueden tener valores mayores y menores a $1 \%$, al igual que los valores de $\mathrm{MgO}$, que varían desde 2\% hasta más de $8 \%$ (Fig. 4). Debido a estas diferencias, se subdivide en Unidad Cima Poás (Botos alto en Ti) y Unidad Cima Poás (Botos bajo en Ti). Las muestras que presentan altos contenidos de $\mathrm{MgO}(>7 \%)$ también son muy bajas en $\mathrm{SiO}_{2}(<52 \%)$, convirtiéndolas en verdaderos basaltos. Los valores de $\mathrm{P} 2 \mathrm{O} 5$ también son variables: hay muestras que presentan valores $<0,3 \%$, mientras que otras superan este valor, los valores de $\mathrm{Ba}$ están en el rango entre 450-950 ppm y para $\mathrm{Zr}$ entre 75 y $175 \mathrm{ppm}$ (Fig. 5). Las diferencias geoquímicas entre estas subunidades podrían estar relacionadas con diferentes episodios de actividad, pero aún falta detalle estratigráfico y cronológico para asegurar esto. La Unidad Cima Poás (Botos alto en Ti) pertenece al Componente Geoquímico Sabana Redonda, mientras que la Unidad Cima Poás
(Botos bajo en Ti) pertenece al Componente Geoquímico Von Frantzius.

\section{Unidad Cima Poás - (Cráter Principal)}

Esta unidad, a diferencia de Botos, no presenta basaltos, pero sí una variación desde andesitas basálticas hasta dacitas. Otra diferencia que existe con las muestras que provienen del cráter Botos es que son calcoalcalinas normales en K (Fig. 3). Finalmente, hay un comportamiento homogéneo al presentar valores bajos en elementos mayores como $<1 \%$ de $\mathrm{TiO}_{2}$ (Fig. 4) y valores $<0,2 \%$ de $\mathrm{P}_{2} \mathrm{O}_{5}$. De igual forma presenta valores más bajos en elementos traza como Ba, $\mathrm{Zr}$ (Fig. 5) y Nb en comparación con otras unidades. Este comportamiento diferencia muy bien estas muestras de unidades como Andesitas La Paz y Poasito. Pertenece al Componente Geoquímico Von Frantzius.

\section{Unidad Bosque Alegre}

Los análisis pertenecientes a esta unidad pertenecen a muestras tomadas tanto de los conos intramaáricos como de depósitos de origen explosivo en los alrededores del cráter. Los conos intramaáricos corresponden con basaltos químicamente muy similares entre sí, mientras que andesitas y andesitas basálticas corresponden con los depósitos explosivos encontrados alrededor del cráter. Ambas poblaciones se encuentran dentro de la serie calcoalcalina baja en $\mathrm{K}$ (Fig. 3). Los niveles de $\mathrm{TiO}_{2}$ son $<1$ $\%$ (Fig. 4). Presenta valores $<0,2$ de $\mathrm{P}_{2} \mathrm{O}_{5}$. Al igual que la Unidad Cerro Congo, esta unidad presenta valores más bajos que las unidades Andesitas La Paz, Poasito y Sabana Redonda en elementos traza como Ba, $\mathrm{Nb}$ y Zr (Fig. 5) por lo que pertenece al Componente Geoquímico Von Frantzius.

\section{Unidad Lapilli Poás}

Con base en la geoquímica y la distribución de sus materiales, Gazel \& Ruiz (2005), asocian 

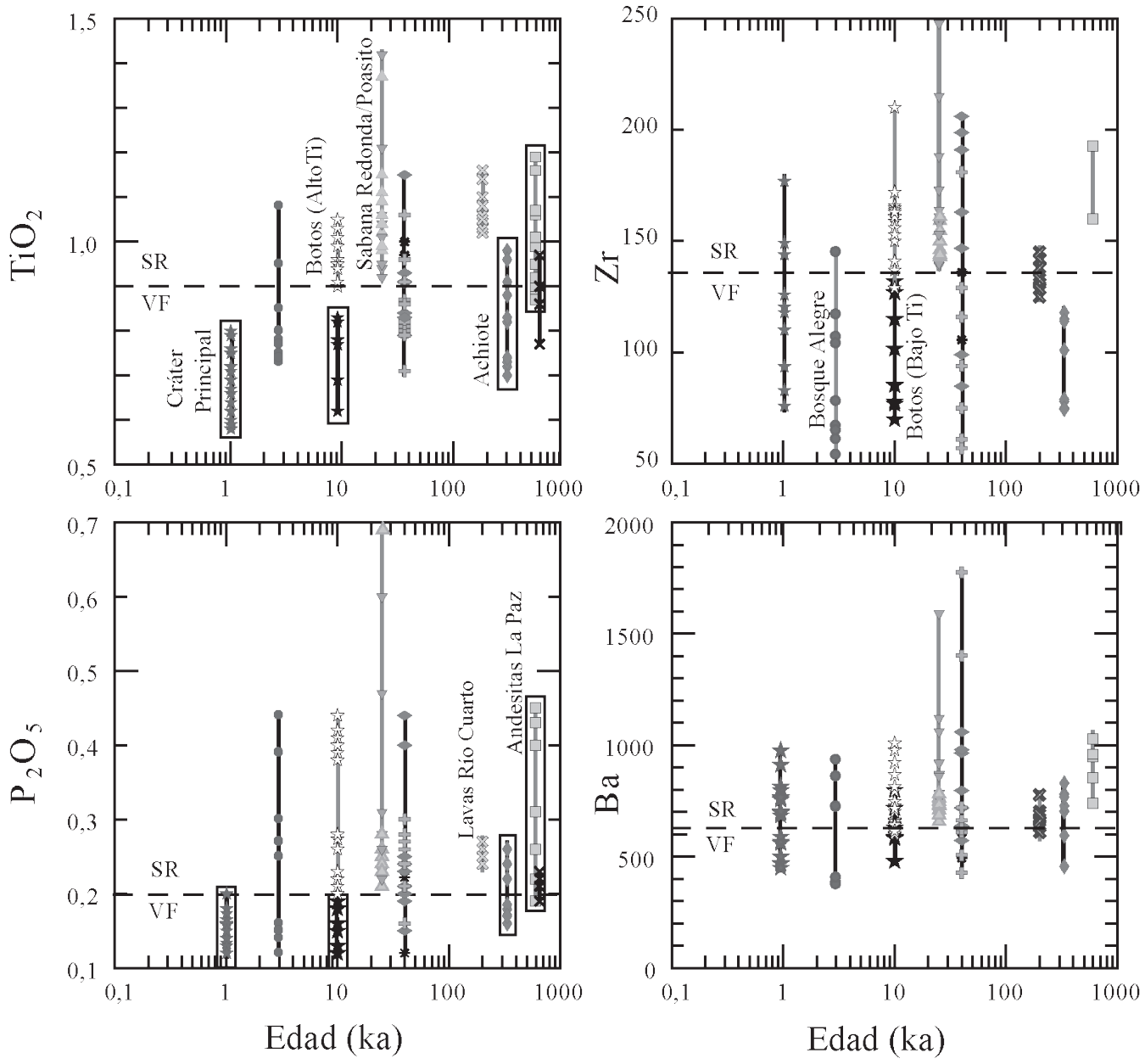

Muestras con $\mathrm{SiO}_{2}<60 \%$

$\mathrm{SR}=$ Componente Geoquímico Sabana Redonda

$\mathrm{VF}=$ Componente Geoquímico Von Frantzius

ț Unidad Cima Poás (Botos alto en Ti)

^ Unidad Cima Poás (Cráter Principal)

$\triangle$ Unidad Sabana Redonda

- Unidad Bosque Alegre

$\nabla$ Unidad Poasito

* Unidad Cima Poás (Botos bajo en Ti)

* Unidad Lavas Río Cuarto

$\diamond$ Unidad Von Frantzius

$\square \quad$ Unidad Andesitas La Paz

\& Unidad Cerro Congo

$\checkmark$ Unidad Achiote

$\times \quad$ Unidad Río Sarapiquí

Fig. 5: Se muestra la variación de contenido de elementos mayores $\mathrm{TiO}_{2}, \mathrm{P}_{2} \mathrm{O}_{5}$ y trazas $\mathrm{Zr}$ y Ba durante la evolución del Volcán Poás en sus distintas unidades geológicas. Los elementos mayores (óxidos) en \% y las trazas en ppm. 
los productos de esta unidad con el cráter Botos, ya que existen diferencias geoquímicas con el Cráter Principal. Según Gazel \& Ruiz (2005), los materiales de esta unidad presentan los contenidos en elementos mayores similares a la geoquímica Sabana Redonda: $\mathrm{TiO}_{2}(0,9-1 \%), \mathrm{Fe}_{2} \mathrm{O}_{3}(9-10$ \%) así como $\mathrm{CaO}(<6,5 \%)$.

\section{EVOLUCIÓN VULCANOLÓGICAY Y PETROLÓGICA}

Este trabajo representa un primer intento por integrar la información disponible y generada en aspectos como geología, petrografía, geocronología y geoquímica del volcán Poás y alrededores, caracterizando un conjunto de unidades volcánicas con el fin de entender sus cambios y diferentes períodos de actividad. El nivel de detalle en el cartografiado geológico del volcán Poás, junto con la base de datos geoquímicos de sus unidades y los datos geocronológicos recopilados para este estudio, brindan una de las pocas oportunidades para estudiar la evolución geoquímica de todo un estratovolcán complejo y voluminoso en Costa Rica y América Central.

\section{Historia geológica}

En los últimos 700 ka, el volcán Poás se ha levantado sobre materiales de la protocordillera, lavas afiricas procedentes de erupciones fisurales y capas de ignimbritas procedentes del volcán Barva. Esto durante diferentes episodios de actividad efusiva, explosiva y erosiva con hiatos de inactividad. Cada una de estas unidades tiene características únicas y sus orígenes son diversos. Hay unidades como Poasito y Sabana Redonda que deben su origen con procesos de extensión originados en la fractura volcano-tectónica en el sector sur del Poás. Otras unidades como Andesitas La Paz, Achiote y Cima Poás, todas principalmente efusivas y virtualmente con un punto central de emisión en común que se correlaciona con actividad típica de un estratovolcán central. Luego, sobre el mismo alineamiento de la fractura volcano-tectónica, pero en el sector norte de volcán, se levantan dos conos volcánicos (Von Frantzius y Cerro Congo) con fases efusivas y explosivas. Durante algunos miles de años han sido erosionados, con picos erosivos probablemente asociados con deslizamientos originados por la actividad sísmica de fallas de rumbo en los flancos del volcán. Finalmente, en el sector norte se han instalado tres cráteres explosivos maáricos, dando origen a las unidades Bosque Alegre y Laguna Kopper, que rompieron las superficies lávicas anteriores, dejando sus depósitos explosivos.

En términos generales, se considera que la fase temporal Proto Poás debería ser $>800$ ka de antigüedad. La fase Paleo Poás tendría posiblemente 3 subfases: (a) Río Sarapiquí sin dataciones aún pero se contempla en $<800-620$ ? ka, (b) Andesitas La Paz de 610-500 ka (especulativamente hasta unos $300 \mathrm{ka}$ ) y (c) la Unidad Achiote con edades de entre 540 y $284 \mathrm{ka}$, que podrían extenderse un poco más en ambos sentidos. Esta fase de la Unidad Achiote sería similar a la que Soto \& Arredondo (2007) describen como Paleo Barva, donde el sector sur de este macizo sitúan a las lavas Bermúdez, datadas en 270 ka por Pérez (2000), con sus equivalentes más afíricas en el sector norte con edades entre 200-260 ka (Carr et al. 2007), que podrían correlacionarse cronológicamente con una fase más tardía de las Andesitas La Paz. Sin embargo, faltan aun más dataciones radiométricas de las unidades norte y sur del Poás para comprobar estas hipótesis.

La fase Neo Poás sería de $<200 \mathrm{ka}$, con un pico de alta productividad de la fábrica de magma en los últimos $56 \mathrm{ka}$, representada por las unidades Lavas Río Cuarto, Achiote, Poasito, Sabana Redonda y los nuevos edificios Von Frantzius, Botos, Congo y los piroclastos indiferenciados que las cubren.

\section{Componentes geoquímicos}

La presencia de dos componentes geoquímicos había sido reportada en Gazel \& Ruiz (2005), 
quienes definieron dos tipos de magmas parentales para las lavas del Poás. El componente "Sabana Redonda" $\left(\mathrm{TiO}_{2}>1 \%\right)$ y el componente "Von Frantzius" $\left(\mathrm{TiO}_{2}<1 \%\right)$, y el resto de datos se modeló como el resultado de mezcla de los dos tipos de magmas. Los nuevos datos confirman la existencia de estos dos tipos de magma, los cuales también pertenecen a dos series magmáticas independientes. Las lavas con tendencia al Componente Geoquímico Sabana Redonda pertenecen a la serie calcoalcalina alta en K. Este componente lo presentan además las unidades Andesitas La Paz, Lavas Río Cuarto, Poasito, la Toba de Lapilli Poás y algunas lavas del cráter Botos. Por otro lado, las rocas donde el Componente Geoquímico Von Frantzius son dominantes, pertenecen a la serie calcoalcalina, y corresponde con las lavas de la zona del Cráter Principal, el cono Von Frantzius, las Unidades Achiote, Bosque Alegre, Cerro Congo y algunas lavas del cráter Botos. Además hay lavas con composiciones intermedias $\left(\mathrm{TiO}_{2} 0,8-1 \%\right)$ que son híbridos entre estos dos componentes (Fig. 3).

La presencia de dos series magmáticas ligadas a dos componentes geoquímicos no pueden ser explicadas por procesos relacionados a la cristalización fraccionada. La Fig. 4 muestra los efectos causados por la cristalización (los vectores muestran los efectos geoquímicos relacionados con la cristalización de diferentes fases), donde se evidencia que definitivamente existen dos series de diferenciación independientes, una alta en $\mathrm{TiO}_{2}$ (Sabana Redonda) y otra relativamente baja (Von Frantzius) y el resto de muestras que posiblemente representan procesos de mezcla. El hecho de que en algunas unidades los componentes magmáticos estén claramente separados y en otras compartan los mismos focos y se mezclen entre sí, sugiere que las cámaras magmáticas en ocasiones han estado separadas y en otras ocasiones han servido para que estos dos componentes se mezclen, generando lavas con composiciones intermedias (Fig.4). Este fenómeno magmático no es exclusivo del Poás en la CVC, pues un comportamiento geoquímico similar ha sido observado en el volcán Irazú (Alvarado et al., 2006).

Mediante diagramas de variación de ciertos elementos mayores como $\mathrm{TiO}_{2}$ y $_{2} \mathrm{O}_{5}$ y trazas como $\mathrm{Zr}$ y Ba a través del tiempo (Fig. 5) se trata de ver la evolución geoquímica que ha experimentado el Poás. Se utilizó una escala logarítmica para graficar las edades de las unidades con el fin de poder mostrar en un mismo gráfico unidades con edades de casi $600 \mathrm{ka}$ y unidades con menos de 2000 años. Las edades que se utilizan en este diagrama son representativas de un rango de actividad para cada unidad (p.ej., las lavas del cráter Principal), en la figura 5 aparecen con una edad de 1 ka pero en realidad representan un rango de edades entre 8 y $0,1 \mathrm{ka}$, los rangos de edades estimados para cada unidad son similares a los dibujados en la figura. 2. Además, en este gráfico solamente se están mostrando las unidades producidas en periodos efusivos del macizo, mientras los hiatos posiblemente representan los episodios explosivos y/o erosivos. Estas apreciaciones en este estudio deben considerarse como una base preliminar, y que dataciones y análisis químicos en proceso, van a ayudar a determinar un panorama más completo en el futuro. Con base en esta información preliminar se pueden establecer las siguientes observaciones: (a) Las unidades que poseen rangos de edades similares presentan comportamientos químicos muy diferentes y en general opuestos entre sí. Es el caso de las unidades Andesitas Las Paz y Río Sarapiquí, Achiote y Lavas de Río Cuarto, Botos alto en $\mathrm{TiO}_{2}$ y Botos bajo en $\mathrm{TiO}_{2}$. Este comportamiento se observa claramente en los diagramas, evidenciando la presencia de dos componentes geoquímicos desde los inicios de la actividad del Poás. (b) Hay una tendencia negativa (de derecha a izquierda) en los valores de $\mathrm{TiO}_{2}$ y $\mathrm{P}_{2} \mathrm{O}_{5}$ para las lavas desde la Andesitas La Paz, seguida por la Unidad Achiote y finalizando con la Unidad Cima Poás Cráter Principal. Sin embargo, entre ellas hay unidades con valores muy altos en estos elementos como lo son la Unidad Poasito y Sabana Redonda, confirmando de nuevo la presencia de los dos componentes geoquímicos independientes entre sí, que en ocasiones han sido emitidos desde diferentes focos (p.ej., Sabana Redonda y Cima Poás Cráter Botos) y en ocasiones comparten el mismo foco (p.eg., Botos alto y Bajo en $\mathrm{TiO}_{2}$, Fig. 5). 


\section{DISCUSIÓN, CONCLUSIONES Y TRABAJOS FUTUROS}

Las unidades que conforman el actual edificio volcánico del Poás podrían tener una edad inferior a $700 \mathrm{ka}$. A lo largo de su historia, las lavas muestran la presencia de dos componentes geoquímicos: Sabana Redonda $\left(\mathrm{TiO}_{2}>1 \%\right)$ y Von Frantzius $\left(\mathrm{TiO}_{2}<1 \%\right)$, el primero relacionado con procesos de descompresión adiabática mientras que el último se relaciona con una fusión por presencia de fluidos provenientes de la zona de subducción (Cameron et al., 2002).

Las edades inferidas para ciertas unidades (Poasito, Río Sarapiquí, Congo) son las mejores aproximaciones con base en la estratigrafía y dataciones aisladas, y para el resto de las unidades se utilizaron edades radiométricas con mejor control estratigráfico. Recomendamos repetir el diagrama de variación de elementos mayores y trazas (Fig. 5) una vez que se lleguen a obtener dataciones radiométricas para las unidades que aún no se tiene certeza de su edad y así mejorar el entendimiento de la evolución del Poás.

Pese a que en este trabajo se obtuvo un satisfactorio control estratigráfico de las diferentes unidades que componen el macizo del volcán Poás, aún quedan problemas estratigráficos y cronológicos que tendrán que ser abordados y resueltos en futuros trabajos. Entre estos problemas se mencionan:

1) Determinar la posición estratigráfica de la ignimbrita del sector norte de la zona de estudio, en la que se han encontrado correlaciones litológicas y químicas con la Formación Tiribí, pero que aún requiere de una datación radiométrica para hacer más fuerte esta correlación o desecharla. En caso de tener una edad superior a $350 \mathrm{ka}$, podría correlacionarse con el miembro Puente de Mulas de la Formación Colima o ser parte de otra unidad aún no estudiada.

2) Conocer la geoquímica y la edad de las rocas del sector sur de la zona de estudio que fueron asociadas en este trabajo con la Unidad Andesitas La Paz. A pesar de que las similitudes litológicas entre las rocas que afloran en el sector sur con las rocas del sector norte de la Unidad Andesitas La Paz son muy buenas, se recomienda realizar análisis geoquímicos y dataciones radiométricas a las rocas del sector sur para así robustecer la correlación.

3) Obtener más edades radiométricas para las rocas de las unidades Achiote, Cerro Congo (lavas basales) y Von Frantzius, así como buscar alguna diferencia temporal entre las lavas Ángel y las lavas Cariblanco de la Unidad Von Frantzius, Laguna Kopper y Cima Poás (Cráter Principal y Botos). Además de intentar caracterizar geoquímicamente los productos emitidos por la Unidad Laguna Kopper.

\section{AGRADECIMIENTOS}

Se le agrade al ICE por las facilidades proporcionadas para realizar este trabajo, tanto por su ayuda en logística en giras de campo, como por información suministrada. Se agradece a Pedro Acosta, Francisco Arias, Sara Mana y Didier Madrigal por su ayuda en el trabajo de campo. Alberto Vargas por sugerencias con el mapa. A Natalia Montes por compartir sus secciones delgadas y muestras, así como suministrar la ubicación de afloramientos en el sector de Grecia. A Dione Barahona por suministrar la descripción de la sección delgada del Cráter Principal. G.J. Soto agradece el aporte financiero de los proyectos $\mathrm{N}^{\circ}$ 830-A7-511 y No 113-A9-509 de la Universidad de Costa Rica y CONARE. Por último se agradece a Wendy Pérez y Siegfried Kussmaul pr las revisiones finales de este documento, asi como a todos todos los que en algún momento cooperaron durante el trabajo de campo y las posteriores etapas de esta investigación.

\section{REFERENCIAS}

ALVARADO, G.E., 1984: Aspectos petrológicosgeológicos de los volcanes y unidades lávicas del Cenozoico Superior de Costa Rica.- 183 págs. Univ. de Costa Rica, San José [Tesis Lic.].

ALVARADO,G.E., 1985: Mapa geológico para el P.H. Toro II.- En: PIEDRA, J., VEGA, O.C., ALVARADO, G. \& LEZAMA, G. (Eds.): Informe geológico-geotectónico 
de avance a la prefactibilidad. P.H. Toro II.- 156 págs. + anexos A y B. Vol. 1 y 2 [Informe interno].

ALVARADO, G.E., 2009: Los volcanes de Costa Rica: Geología, historia, riqueza natural y su gente [ $3^{\mathrm{a}}$ ed.].- 335 págs +16 láminas. EUNED, San José.

ALVARADO, G.E.\&CLIMENT,A., 1985:Informe sismológico para la etapa de avance a la prefactibilidad.- En: PIEDRA, J., VEGA, O.L., ALVARADO, G. \& LEZAMA, G. (Eds.): Proyecto Hidroeléctrico Toro II. ICE, San José: 1-46 [Inf. Interno].

ALVARADO, G.E. \& CARR, M.J., 1993: The Platanar-Aguas Zarcas volcanic centers, Costa Rica: spatial-temporal association of Quaternary cal-alkaline and alkaline volcanism.- Bull. Volcanol. 55: 443-453.

ALVARADO, G.E. \& SALANI, F.M., 2004: Tefroestratigrafía (40 000-2000 a.P.) en el sector Caribe de los volcanes Barva, Congo y Hule, Cordillera Central, Costa Rica.Rev. Geol. Amér. Central, 30: 59-72.

ALVARADO, G.E., CARR, M.J., TURRIN, D.B., SWICHER III, C.C., SCHMINCKE, H.-U. \& HUDNUT, K.W., 2006: Recent volcanic history of Irazú volcano, Costa Rica: Alternation and mixing of two magma batches, and pervasive mixing.- En ROSE, W.I., BLUTH, G.J.S., CARR, M..J., EWERT, J., PATINO, L.C., \& VALLANCE, J. (eds): Volcanic hazards in Central America.- Geol. Soc. Amer. Spec. Pap. 412: 259-276.

BORGIA, A., BURR, J., MONTERO, W., MORALES, L.D. \& ALVARADO, G.E., 1990: Fault propagation folds induced by gravitational failure and slumping of the Central Costa Rica Volcanic Range: Implications for large terrestrial and Martian volcanic edifices.- J. Geophys. Res. 95: 14357-14382.
CAMERON, B.I., WALTER, J.A., CARR, M.J., PATINO, L.C., MATIAS, O. \& FEIGENSON, M.D., 2002: Flux versus decompression melting at stratovolcanoes in southeastern Guatemala.- J. Volcanol. Geotherm. Res. 119: 21-50.

CAMPOS, L.A., CASTRO, L., GAZEL, E., MONTES, N., MURILLO, S., RAMÍREZ, S., RUIZ, P. \& SEQUEIRA, M., 2004: Geología, geomorfología, amenazas naturales del Cantón de Poás, Alajuela.- 60 págs. Univ de Costa Rica, San José [Inf. Campaña Geol.].

CARR, M.J., 2002: CAGeochem database.-http:// www.rci.rutgers.edu/ carr/,consulta junio 2009.

CARR, M.J., ALVARADO, G.E., BOLGE, L., LINSAY, F., MILIDAKIS, K., TURRIN, B., FEIGENSON, M. \& SWISHER III, C., 2007: Element fluxes from the volcanic front of Costa Rica and Nicaragua.Geochem. Geophys. Geosyst., 8 Q06001. DOI: 10.1029/2006GC001396.

CIGOLINI, C., KUDO, A.M., BROOKINS, D.G. \& WARD, D., 1991: The petrology of Poás Volcano lavas: basalt-andesite relationship and their petrogenesis within the magmatic arc of Costa Rica.- J. Volcanol. Geotherm. Res. 48: 367-384.

ECHANDI , E., 1981: Unidades volcánicas de la vertiente $\mathrm{N}$ de la cuenca del río Virilla.123 págs. Univ. de Costa Rica, San José [Tesis Lic.].

FERNÁNDEZ, M., 1969: Las unidades hidrogeológicas y los manantiales de la vertiente norte de la cuenca del río Virilla.- 56 págs. Investigaciones de aguas subterráneas en Costa Rica. Informe Técnico 27. [Informe Interno].

GANS, P.B., MACMILLAN, I., ALVARADO, G., PÉREZ, W \& SIGARÁN, C., 2002: 
Neogene evolution of the Costa Rican Arc.- [Abstract] Geol. Soc. Amer. 2002 Annual Meeting, Denver, October 2002.

GAZEL, E. \& RUIZ, P., 2005: Los conos piroclásticos de Sabana Redonda: Componente magmático enriquecido del volcán Poás, Costa Rica.- Rev. Geol. Amér. Central, 33 : 45-60.

GAZEL, E., ALVARADO, G.E., OBANDO, J. \& ALFARO, A., 2005: Evolución magmática del arco de Sarapiquí, Costa Rica.- Rev. Geol. Amér. Central, 32: 3-13

HANNAH, R.S., VOGEL, T.A., PATINO, L.C., ALVARADO, G.E., PÉREZ, W \&, SMITH, D.R., 2002: Origin of silicic volcanic rocks in Central Costa Rica: a study of a chemically variable ash-flow sheet in the Tiribi Tuff.- Bull. Volcanol. 64: 117-133.

KRUSHENSKY, R.D \& ESCALANTE, G., 1967: Activity of Irazú and Poás volcanoes, Costa Rica, Nov.1964/Jul. 1965.- Bull. Volcanol. 31:75-84.

KUSSMAUL, S., 1988: Comparación petrológica entre el piso del valle central y la cordillera central de Costa Rica.- Ciencia y Tecnología, 12(1-2): 109-116.

KUSSMAUL, S. \& SPRECHMANN, P., 1982: Estratigrafia de Costa Rica (América Central) II: Unidades litoestratigráficas ígneas.- Actas V Congreso Latinoamericano de Geología, Buenos Aires, I: 73-79.

KUSSMAUL, S., PANIAGUA, S. \& GAÍNZA, J., 1982: Recopilación, clasificación e interpretación petroquímica de las rocas ígneas de Costa Rica.- Inf. Sem. IGN, 1982(2): 17-79.

MALAVASSI, E., 1991: Magma sources and crustal processes at the terminous of the Central American Volcanic Front.- 435 págs. Univ de Santa Cruz, California [Tesis Ph.D.].

MALAVASSI, E., GILL, J.B. \& TRIMBLE, D., 1990. Nuevas dataciones radiométricas del alineamiento volcánico de Poás (Costa Rica): Contribución a la evaluación de peligros volcánicos.- [Programas y Resúmenes de Ponencias] [s.p.], VII Congreso Geológico de América Central, 19-23 de noviembre de 1990, San José, Costa Rica.

MARSHALL, J.S. \& IDLEMAN, B.D., 1999: ${ }^{40} \mathrm{Ar} /{ }^{39} \mathrm{Ar}$ age contraints on Quaternary landscape evolution of the central volcanic arc and Orotina debris fan, Costa Rica.Abstr. GSA Annual Meeting 06426.

MARSHALL, J.S.,IDLEMAN,B.D., GARDNER, T.W. \& FISHER, D.M., 2003: Landscape evolution within a retreating volcanic arc, Costa Rica, Central America.- Geology, 31(5): 419-422.

McBIRNEY, W., \& WILLIAMS, H., 1965. Volcanic history of Nicaragua.- Univ. Calif. Publ. Geol. Sci., 55: 1-65.

MELSON, W. G., SÁENZ, R., BARQUERO, J. \& FERNÁNDEZ., 1988: Edad relativa de las erupciones del Cerro Congo y Laguna Hule.- Boletín Vulcanología, Univ Nacional, Heredia, 19: 8-10.

MONTERO, W., SOTO, G.J., ALVARADO, G.E. \& ROJAS, W., 2010: División del deslizamiento tectónico y transtensión dentro del en el macizo del volcán Poás, Costa Rica.- Rev. Geol. Amér. Central [en este volumen].

MONTES, N., 2007: Clasificación de los suelos a partir de sus propiedades físicas, mecánicas e hidráulicas y su relación con el potencial de infiltración, en el sector occidental del cantón de Grecia, Alajuela.- 97 págs. Univ. de Costa Rica, San José [Tesis Lic.]. 
PANIAGUA, S., 1985: Geoquímica de los elementos traza de las vulcanitas del Cenozoico superior de la región central de Costa Rica.Rev. Geol. Amér. Central, 2: 33-62.

PATINO, L. CARR, M.J., FEIGENSON, M.D.,2000: Local and regional variations in Central America arc lavas controlled by variations in subducted sediment input.- Contrib. Mineral. Petrol. 138, 265283. DOI: $10.1007 / \mathrm{s} 004100050562$.

PECCERILLO, A. \& TAYLOR, S.R., 1976: Geochemistry of Eocene calc-alkaline volcani rocks from the Kastamonu area, northen Turkey.- Contributions to Mineralogy and Petrology, 58: 63-81.

PERALDO, G. \& MONTERO, W., 1999: Sismología histórica de América Central.347 págs. Ed. IPGH, México.

PÉREZ, W., 2000: Vulcanología y petroquímica del evento explosivo del Pleistoceno Medio (0,33 Ma) del Valle Central, Costa Rica.- 170 págs. Univ. de Costa Rica, San José [Tesis Lic.].

PÉREZ, W., ALVARADO, G.E. \& GANS P., 2006: The 322 ka Tiribí Tuff: stratigraphy, geochronology and mechanisms of deposition of the largest and most recent ignimbrite in the Central Valley, Costa Rica.- Bull. Volcanol. 69: 25-40.

PROSSER, J.T., 1983: The Geology of Poás Volcano, Costa Rica.- 165 págs. Dartmouth College, Hanover, New Hampshire [Master Thesis].

PROSSER, J.T. \& CARR, M.J., 1987: Poás Volcano, Costa Rica: Geology of the summit region and spatial and temporal variations among the most recent lavas.J. Volcanol. Geotherm. Res. 33:131-146.

RED SISMOLÓGICA NACIONAL (RSN: ICEUCR), 2009: El terremoto de Cinchona del jueves 8 de enero de 2009.- Rev. Geol. Amér. Central, 40: 91-95.

ROJAS, L., 1993: Estudio geológico-geotécnico de un sector del P. H. Laguna Hule.- 42 págs. Univ. de Costa Rica, San José. [Inf. Campaña Geol.].

SALANI, M. F. \& ALVARADO G.E., 2010. El maar poligenético de Hule (Costa Rica). Revisión de su estratigrafía y edades. Rica.-Rev. Geol. Amér. Central, (este volumen).

SOTO, G.J., 1994. Volcanología Física.- En: DENYER, P. \& KUSSSMAUL, S. (comps.) Atlas Geológico del Gran Área Metropolitana.Ed. Tecnol. Costa Rica: 131-146.

SOTO, G.J., 1999: Geología Regional de la Hoja Poás (1:50 000) Instituto Costarricense de Electricidad: 1 hoja.- En: ALVARADO, G.E. \& MADRIGAL, L.A. (eds): Estudio Geológico-Geotécnico de Avance a la Factibilidad del P.H. Laguna Hule.- 30 págs. ICE, San José [Inf. Interno].

SOTO, G.J. \& ALVARADO, G.E., 1989: Procesos volcánicos asociados con el agua subterránea. El caso de los volcanes Arenal y Poás, Costa Rica.- Memoria del III Congr. Nac. Recursos Hídricos, San José: 249-261.

SOTO, G.J \& ARREDONDO, S.G., 2007: Chronostratigraphic summary of Barva Formation (Costa Rica).- [Abstract], Worshop to integrate Subduction Factory and Seismogenetic Zone Studies in Central America, junio 18-22, 2007, Heredia, Costa Rica, p.103 (en cibersitio http:// www.nsf-margins .org/Costa Rica2007/ index.html).

SOTO, G., PÉREZ, W. \& ARREDONDO, S., 2008: ¿Cuán extensa y voluminosa es la Formación Tiribi, Costa Rica? Nuevos hallazgos y reinterpretaciones.- [Resumen]. 
IX Congreso Geológico de América Central, San José, julio 2008.

SOTO, G.J., ALVARADO, G.E., SALANI, F.M., RUIZ, P. \& HURTADO DE MENDOZA, L., 2010: The Hule and Río Cuarto maars, Chapter One: The beginning.- [Abstract] IAVCEI Commission of Volcanic Lakes, 7th Workshop on Volcanic Lakes Costa Rica, 10-19 March 2010: 37.

STUIVER, M. \& REIMER, P.J., 1993: Extended ${ }^{14} \mathrm{C}$ database and revised CALIB radiocarbon calibration program.- Radiocarbon, 35: 215-230.

THORPE, C.A., LOCKE, G.C. \&. BROWN, P.W. 1981: Magma chamber below Poás volcano, Costa Rica.- J. Geol. Soc. 138: 367-373.

TOURNON, J., 1984: Magmatismes du Mesozoique a l'actuel en Amérique
Centrale: l'exemple de Costa Rica, des ophiolites aux andésites.- 335 págs. Mém. Sc. Terre Univ. Pierre et Marie Curie 84-49.

VAN DER PLICHT, J., BECK, J.W., BARD, E., BAILLIE, M.G.L., BLACKWELL, P.G., BUCK, C. E., FRIEDRICH, M., GUILDERSON, T.P., HUGHEN, K.A., KROMER, B., McCORMAC, F.G., BRONK RAMSEY, C., REIMER, P.J., REIMER, R.W., REMMELE, S., RICHARDS, D.A., SOUTHON, J.,R STUIVER, $M$ \& WEYHENMEYER, C.E., 2004: NotCal04- Comparasion/ Calibration ${ }^{14} \mathrm{C}$ Records 26-50 cal kyr BP. Radiocarbon, 46(3): 1225-1238.

WILLIAMS, H., 1952: Volcanic history of the Meseta Central Occidental , Costa Rica.Univ. California Pub. Geol. Sc. 29(4): 145-180. 